\title{
Six 1 is a key regulator of the developmental and evolutionary architecture of sensory neurons in craniates
}

\author{
Hiroshi Yajima ${ }^{1}$, Makoto Suzuki ${ }^{2}$, Haruki Ochi ${ }^{3}$, Keiko Ikeda ${ }^{1}$, Shigeru Sato ${ }^{1}$, Ken-ichi Yamamura ${ }^{4}$, Hajime Ogino ${ }^{5}$, \\ Naoto Ueno ${ }^{2}$ and Kiyoshi Kawakami ${ }^{\text {* }^{*}}$
}

\begin{abstract}
Background: Various senses and sensory nerve architectures of animals have evolved during adaptation to exploit diverse environments. In craniates, the trunk sensory system has evolved from simple mechanosensory neurons inside the spinal cord (intramedullary), called Rohon-Beard (RB) cells, to multimodal sensory neurons of dorsal root ganglia (DRG) outside the spinal cord (extramedullary). The fish and amphibian trunk sensory systems switch from RB cells to DRG during development, while amniotes rely exclusively on the DRG system. The mechanisms underlying the ontogenic switching and its link to phylogenetic transition remain unknown.

Results: In Xenopus, Six 1 overexpression promoted precocious apoptosis of RB cells and emergence of extramedullary sensory neurons, whereas Six 1 knockdown delayed the reduction in RB cell number. Genetic ablation of Six 1 and Six4 in mice led to the appearance of intramedullary sensory neuron-like cells as a result of medial migration of neural crest cells into the spinal cord and production of immature DRG neurons and fused DRG. Restoration of SIX1 expression in the neural crest-linage partially rescued the phenotype, indicating the cell autonomous requirements of SIX 1 for normal extramedullary sensory neurogenesis. Mouse Six 1 enhancer that mediates the expression in DRG neurons activated transcription in Xenopus RB cells earlier than endogenous six 1 expression, suggesting earlier onset of mouse SIX1 expression than Xenopus during sensory development.
\end{abstract}

Conclusions: The results indicated the critical role of Six 1 in transition of RB cells to DRG neurons during Xenopus development and establishment of exclusive DRG system of mice. The study provided evidence that early appearance of SIX1 expression, which correlated with mouse Six 1 enhancer, is essential for the formation of DRG-dominant system in mice, suggesting that heterochronic changes in Six 1 enhancer sequence play an important role in alteration of trunk sensory architecture and contribute to the evolution of the trunk sensory system.

Keywords: Dorsal root ganglia, Enhancer, Evolution, Neural crest cell, Rohon-Beard cell, Sensory neuron, Six genes

\section{Background}

Trunk sensory neurons convey somatic and visceral information to the central nervous system (CNS). Rohon-Beard (RB) cells are known to mediate the sensory pathway in fish and amphibian larvae [1-5]; however, this cell type has not been identified in avian and mammalian species [6,7] (Figure 1A). In fish and amphibians, RB cells are located in the dorsal part of the spinal cord and have peripheral

\footnotetext{
* Correspondence: kkawakam@jichi.ac.jp

'Division of Biology, Center for Molecular Medicine, Jichi Medical University, 3311-1 Yakushiji, Shimotsuke, Tochigi 329-0498, Japan

Full list of author information is available at the end of the article
}

and central neurites. The peripheral neurites innervate the skin of the trunk, while the central neurites descend and ascend over several segments within the spinal cord, ultimately reaching the brainstem [2,8]. At later larval stages, RB cells undergo cell death by apoptosis. Concomitantly, neural crest cell (NCC)-derived extramedullary sensory ganglia (dorsal root ganglia; DRG) develop and begin to process mechanosensory inputs [9]. At present, evidence suggests that the body organization of cephalochordate Amphioxus reflects the early primitive condition of chordate. Although it lacks extramedullary sensory neurons, equivalent to DRG neurons, it has two types of 


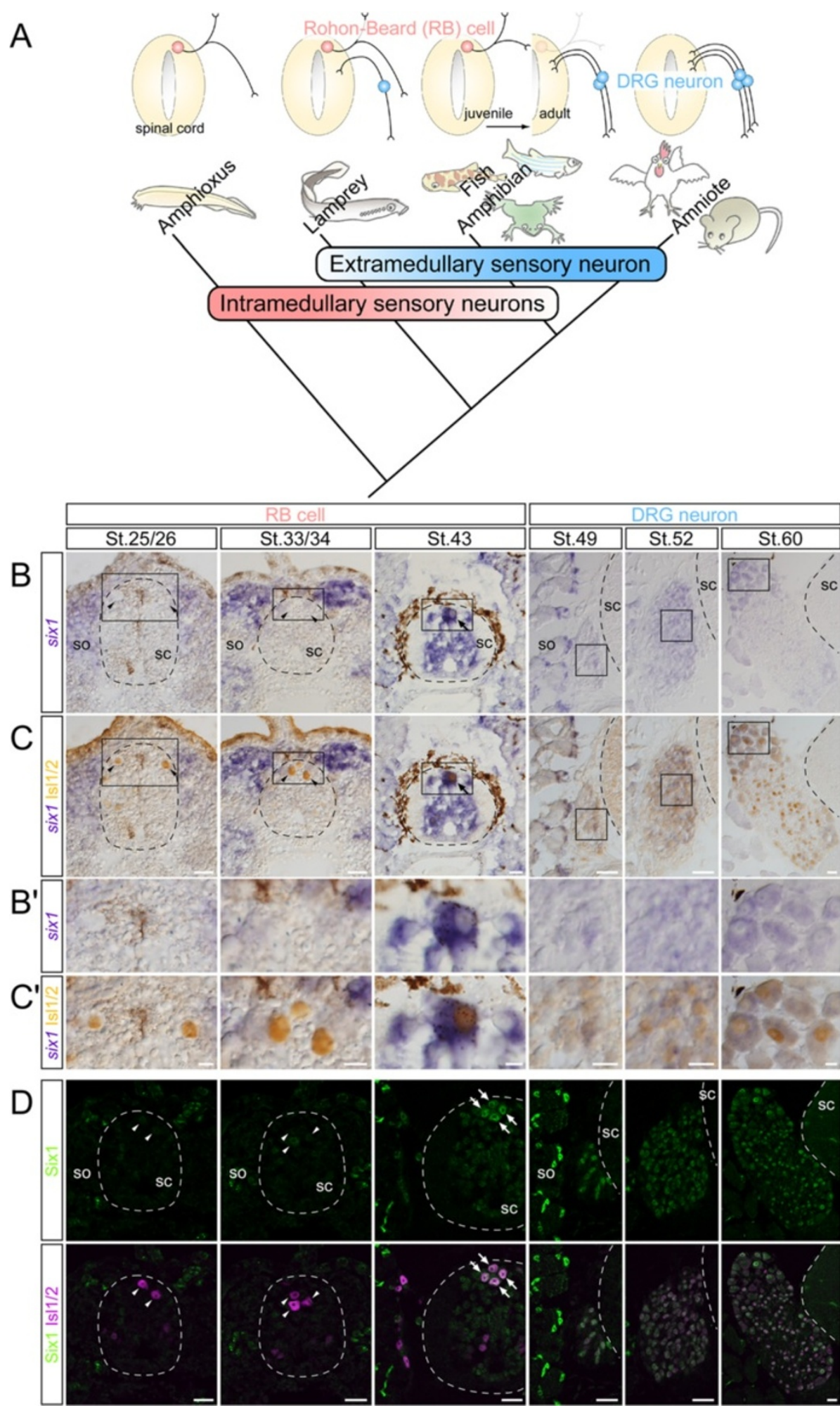

Figure 1 (See legend on next page.) 
(See figure on previous page.)

Figure 1 Expression of Xenopus Six1 appears during transition from Rohon-Beard cells to dorsal root ganglia. (A) Cladogram showing the succession of primary sensory neurons of chordates in the trunk. Intramedullary primary sensory neurons, called Rohon-Beard (RB) cells, dorsal cells, Retzius bipolar cells or DRiii cells (pink), are recognized in various species [5,6] - including amphioxus [13]; lampreys: Lampetra planeri [14], Lampetra japonica [15]; fish: Lepisosteus osseus [1], Raja (Dipturus) batis [16], Scyliorhinus torazame [17], Danio rerio [18]; and amphibian: Ambystoma punctatum [3], Xenopus laevis [4], Rana pipiens [19], Rana catesbeiana [20], Ceratophrys ornata [21], Eleutherodactylus coqui [22] - but not in amniotic vertebrates [6,7]. Craniates have extramedullary sensory neurons (blue) that are derived from neural crest cells and form dorsal root ganglia (DRG). (B-D) Distribution of Six 1 mRNA and protein in the trunk region of Xenopus embryos (dorsal side: top of transverse sections). Developmental stages are indicated at top line. Arrowheads: Six1-negative RB cells; arrows: Six1-positive RB cells. (B, C) In situ hybridization of six1 (purple) is followed by immunostaining of Isl1/2 (orange), marking RB cells and DRG neurons. (B', $\mathbf{C}^{\prime}$ ) Magnified views of the areas indicated by the

rectangles in $\mathbf{B}$ and $\mathbf{C}$. (D) Detection of Six 1 (green) and Is $1 / 2$ (magenta) by immunofluorescence in sections adjacent or alternate to those in $\mathbf{B}$ and $\mathbf{C}$. Dashed lines demarcate the position of the spinal cord. sc, spinal cord; so, somite. Scale bars: $25 \mu \mathrm{m}$ (B-D) and $10 \mu \mathrm{m}$ (B', $\mathbf{C}^{\prime}$ ).

intramedullary neurons comparable to RB cells of anamniotes, Retzius bipolar cells in larvae $[10,11]$ and DRiii cells in adult [12]. In agnathan lampreys, both RB cells and extramedullary sensory neurons are present, but their spinal roots are primitive and asymmetrical [7]. Due to the ontogenic transition in anamniotes from RB cells to DRG neurons and phylogenetic disappearance of $\mathrm{RB}$ cells in amniotes, intramedullary cells are regarded as the prototype of sensory neurons in chordates (Figure 1A).

Both RB cells and NCCs arise from the cells present at the border of the neural- and non-neural ectoderm and both require similar inductive signals including bone morphogenetic proteins [23]. Notch/Delta signaling alternatively determines their fates; it promotes RB cell fate at the expense of NCC-derived cell types [24,25]. Whereas NCCs undergo epithelial-to-mesenchymal transition and migrate to their final destinations, including DRG [26], RB cells migrate medially from the border and are finally incorporated into the medulla [27-29]. RB cells extend their neurites and mediate the sensory circuits required for rhythmic swimming and predator avoidance [30,31]. At the approach of metamorphosis, the functions of RB cells are superseded by DRG neurons, and the death of RB cells is induced by the attenuation of TrkC1/NT-3 signaling [32]. Although previous studies shed light on the induction, specification and differentiation processes of $\mathrm{RB}$ cells in zebrafish and Xenopus [33], the molecular mechanisms underlying the replacement of RB cells with DRG neurons remain largely unknown. Unveiling such mechanisms should enhance our understanding of the evolution of sensory architecture, particularly the emergence of DRG in craniates and subsequent disappearance of RB cells in amniotes.

In the cranial region, the Six 1 homeobox gene is considered the main player in the genesis of sensory organs: loss of function of $\operatorname{Six} 1$ causes severe defects in various sensory organs that originate from the cranial sensory placodes in zebrafish [34,35], Xenopus [36,37], mouse [38-43] and humans [44-46]. The expression of Six4, another Six family gene, shows a similar pattern, and simultaneous loss of both genes aggravated the defects in mice [47-49]. While Six1 and Six4 are also expressed in
DRG in the trunk [40,50], the functional significance of the two genes in the development of DRG neurons and RB cells has not been explored.

In the present study, we found that Six1 is expressed in Xenopus RB cells just before apoptotic cell death. Experiments involving Six1 overexpression and knockdown demonstrated that Six 1 is a key molecule for the ontogenic transition of RB cells to DRG neurons during development. Moreover, in mice, SIX1 and SIX4 were essential for the normal development of DRG, and loss of both genes allowed the emergence of intramedullary sensory neuron-like cells, as a result of immigration of NCCs into the spinal cord. We also investigated the molecular basis of the differential onset of Six 1 expression in both Xenopus and mouse. The results showed changes in the activity of a conserved enhancer. Based on these results, we suggest that heterochronic shift in Six1 expression contributes to phylogenetic transition in the architecture of sensory neurons.

\section{Results}

\section{Six 1 expression is turned on immediately before the} onset of Xenopus Rohon-Beard cell apoptosis

To investigate the functions of both Six1 and Six4 in the development of trunk sensory neurons, we first examined their expression patterns in Xenopus embryos (Figure 1B, C). RB cells are characterized by their large size and dorsal location in the spinal cord and their nuclei are positive for Isl1/2(Islet1/2) [51,52]. No mRNA or protein expression of Six1 and Six 4 was observed in RB cells at stages (St.) 16/17, 25/26 and 33/34 (arrowheads in Figure 1B,C; Additional file 1). However, Six 1 mRNA and protein expression was recognized in RB cells at St. 43 (arrows in Figure $1 \mathrm{~B}, \mathrm{C}$ ). The majority of DRG neurons (identified by their Isl1/2-positive nuclei and location within the dorsal root) were positive for Six1 from St. 49 to 60 . The number of RB cells started to decrease at around St. 46 due to apoptosis [9]. These findings indicate that Six1 expression appears before apoptosis of RB cells, and persists during DRG formation in Xenopus development, although both are trunk sensory neurons. 


\section{Six 1 controls the transition from Rohon-Beard cells to dorsal root ganglia during Xenopus development}

The above findings suggested that Six1 is a key regulator of apoptotic death of RB cells and the development of DRG during the transition of sensory neurons in Xenopus. To test this notion, we investigated the effects of Six1 overexpression and knockdown (Figure 2). To avoid any disturbance of early embryonic development, especially placodal development and early neuronal differentiation [36], we utilized a steroid hormone-inducible system [53]. We generated mRNA encoding Xenopus Six1 fused to the glucocorticoid receptor ligand-binding domain (GR) (Six1GR) and injected it into V1.2 blastomeres at the 16-cell stage. During normal development, the blastomeres give rise to the dorsal spinal cord and ectoderm, including $\mathrm{RB}$ cells [54] (Additional file 2A). Six1-GR was then activated by adding dexamethasone (Dex) at St. 16/17, at the time when the majority of RB cells had already exited the cell cycle [55]. The embryos were analyzed at St. 25/26.

In all experiments, enhanced GFP (EGFP) mRNA was co-injected to trace the distribution and lineage of the injected cells. RB cells, which are positive for both Isl1/2 and Tlx3 (XHox11L2) [56], were effectively labeled with EGFP in embryos injected with mRNA encoding $\beta$-globin as a control (Figure 2A). Dex-treatment did not alter the distribution or number of $\mathrm{RB}$ cells, or the proportion of EGFP-positive RB cells in embryos injected with $\beta$-globin mRNA (39.5 \pm 2.6 cells in -Dex, $\mathrm{n}=12 ; 34.9 \pm 2.3$ cells in + Dex, $n=11$; Figure 2B,F). The number of RB cells in embryos injected with Six1-GR mRNA decreased significantly to $25.5 \pm 2.0$ cells $(\mathrm{n}=17, p=0.0002)$ after Dextreatment, compared with Dex-untreated control (40.1 \pm 2.8 cells, $\mathrm{n}=16$; Figure $2 \mathrm{C}, \mathrm{D}, \mathrm{F})$ and with $\beta$-globin mRNAinjected embryos (Figure 2F). The fraction of EGFPpositive RB cells was also reduced by Dex-treatment (Figure 2G). To determine whether the observed reduction in RB cells was due to apoptosis, which is known to occur later during normal development, we performed immunostaining for cleaved CASP3 (Caspase-3). No signal was detected in the EGFP-positive cells within the dorsal spinal cords of embryos injected with Six1-GR mRNA and untreated, whereas the signal was clearly detected in Dextreated embryos at St. 25/26 (Figure 2H). These findings suggest that precocious expression of Six 1 accelerates the disappearance of RB cells, at least in part, through the induction of apoptosis.

Surprisingly, at St. 33/34, Isl1/2- and Tlx3-doublepositive cells were observed outside the spinal cord in the Six1-GR-overexpressing and Dex-treated embryos $(7.2 \pm 1.2$ cells, $\mathrm{n}=13)$, but rarely in the control embryos $(1.1 \pm 0.6$ cells in $\beta$-globin -Dex, $n=9 ; 0.4 \pm 0.3$ cells in $\beta$-globin + Dex, $\mathrm{n}=9 ; 1.0 \pm 0.3$ cells in Six1-GR -Dex, $\mathrm{n}=12$; Figure 2E,I,J). Importantly, most of these cells were positive for EGFP ( $93.5 \pm 3.3 \%)$, suggesting cell-autonomous effect of Six1-GR activation. Although Isl1/2 and Tlx3 are markers for both DRG neurons and RB cells (Additional file $2 \mathrm{~B}$ ), the extramedullary and ventrolateral location of Isl1/2- and Tlx3-double-positive cells suggests that these sensory neuron-like cells are closely related to DRG neurons (Figure 2K). Taken together, these findings suggest that overexpression of Six1 promotes premature differentiation of extramedullary neurons in Xenopus embryos.

To evaluate the effects of loss-of-function of Six1 on the transition of trunk sensory neurons, small interfering RNAs (siRNAs) were introduced into the dorsal spinal cord through electroporation (Figure 2L). We generated three different siRNAs for Six1 (Figure 2M). The knockdown efficacy of the mixture of Six 1 siRNAs was verified in HEK293 cell line (Additional file 2C). To avoid disturbance of early development by Six1 siRNAs, electroporation was performed on St. 34/35 embryos, before the onset of cell death [9]. Because the maximum number of RB cells appears at St. 41 and the number falls thereafter [9] (Additional file 2D), counting of RB cells in the trunk region (in somite pairs 1 to 9) was conducted at St. 45/46 (Figure $2 \mathrm{~N}$ ). The number of $\mathrm{RB}$ cells significantly increased from $70.1 \pm 4.6$ cells in the control embryos ( $n=$ 21) to $90.5 \pm 6.4$ cells in embryos electroporated with the Six1 siRNAs $(\mathrm{n}=15, p=0.01$; Figure $2 \mathrm{~N})$. To validate the specificity of the Six1 siRNAs, we performed a rescue experiment by employing Six1-containing silent mutations in the siRNA target sequences (Figure $2 \mathrm{M}$ ), which was resistant to our siRNAs (Additional file 2C). Co-electroporation of Six 1 siRNAs with the mutated six 1 mRNA reversed the knockdown effect of siRNAs (50.2 \pm 3.6 cells, $\mathrm{n}=22, p=$ 0.000001 ) (Figure $2 \mathrm{~N}$ ), confirming that the knockdown of Six1 itself causes a delay in the reduction of the number of RB cells.

Taken together, the above findings indicate that early expression of Six1 leads to a decrease in the number of $\mathrm{RB}$ cells, while it promotes extramedullary sensory neurogenesis. Additionally, knockdown of Six1 leads to delay in the reduction of RB cell number. Based on these results, it is conceivable that Six1 is involved in purging $\mathrm{RB}$ cells and promoting the formation of DRG during Xenopus development.

\section{SIX1 and SIX4 control the development of mouse dorsal root ganglia}

We next examined the roles of SIX1 and SIX4 in the development of sensory neurons in the trunk of mice. Immunofluorescence staining with specific SIX1 and SIX4 antibodies [39,48] (Additional file 3A) showed similar distribution patterns for SIX1 and SIX4 proteins in the DRG at embryonic day (E) 11.5 (Additional file 3B). SIX1 was located in approximately $50 \%$ of the ISL1/2-positive neurons (Figure 3A,B), but not in SOX10-positive undifferentiated NCCs or glia (Figure $3 \mathrm{C}$ ). We described previously 


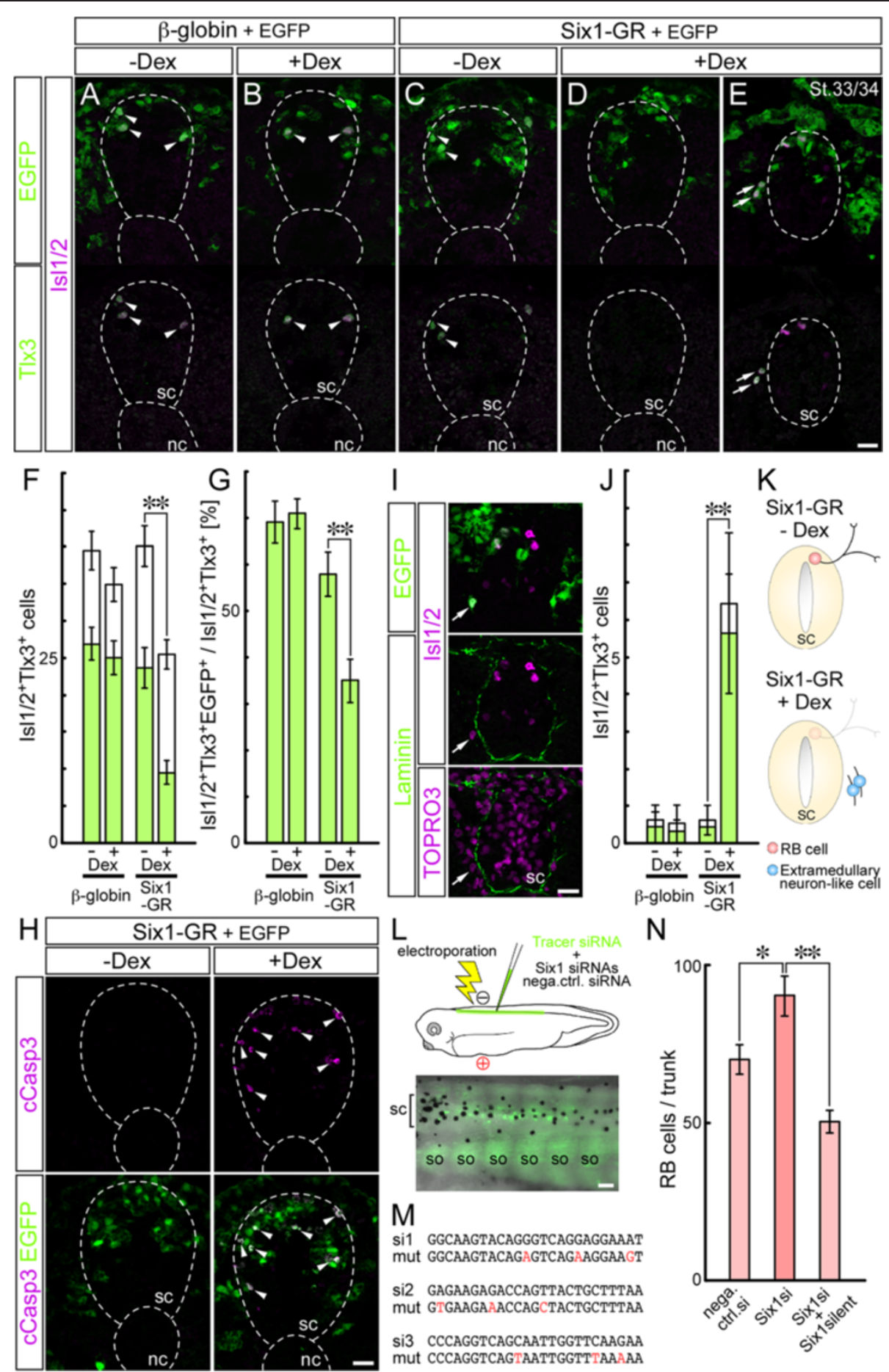

Figure 2 (See legend on next page.) 
(See figure on previous page.)

Figure 2 Six 1 mediates the developmental transition of trunk sensory neurons during Xenopus development. (A-K) Earlier expression of Six1 reduces the number of Rohon-Beard (RB) cells and promotes differentiation of extramedullary sensory neurons in Xenopus. (A-E) The combinations of injected mRNAs and treatment with dexamethasone (Dex) are indicated at the top. Arrowheads: enhanced GFP (EGFP)-positive RB cells, which are marked with both Isl1/2 (magenta) and Tlx3 (green) in the spinal cord (sc) at St. 25/26 (A-D). Arrows: EGFP-, Isl1/2- and Tlx3triple-positive cells outside sc at St. 33/34 (E). (F) Quantification of RB cells and (G) percentage of EGFP-positive RB cells in $250 \mu$ m of the thoracic level at St. 25/26. White bars: total number of RB cells, green bars: EGFP-positive cells. (H) EGFP-and cleaved CASP3 (cCasp3)-double-positive cells (arrowheads) are noted in Six1-GR + Dex. (I) In Six1-GR + Dex embryos, Isl1/2- and EGFP-double positive cells (arrow) are located outside sc. Laminin (green): sc outline, TOPRO3 (magenta): nuclei. (J) Quantification of Isl1/2- and TIx3-double positive cells outside sc. White bars: total number of cells, green bars: EGFP-positive cells. (K) Schematic representation of the results. Activation of Six 1 reduced the number of RB cells (pink) in sc and enhanced the differentiation of DRG neuron-like cells (blue) outside sc. (L-N) siRNA mediated knockdown of Six 1 increased the number of RB cells. (L) Top: schematic representation of electroporation of Xenopus embryo. Bottom: merged picture of epifluorescence and bright field in obliquely dorsal view of the trunk at St. 45. Fluorescein isothiocyanate-labeled control small interfering RNA (siRNA) persists in the dorsal sc. (M) si1, si2 and si3: siRNA targeted sequences in six 1; mut: three silent mutations, each corresponding to siRNA targeted regions in mutated six1. (N) Number of Isl1/2-positive RB cells in the trunk (level in somite (so) pairs 1 to 9) at St. 45/46. Data are mean \pm standard error of the mean. ${ }^{*} p<0.01 ;{ }^{* *} p<0.001$. Dashed lines demarcate the position of sc and notochord (nc). Scale bars: $100 \mu \mathrm{m}$ (L) and $25 \mu \mathrm{m}$ (A-K,M,N).

the generation of Six 1 and Six4 knockout alleles that harbor EGFP and LacZ genes, respectively [48,57]. Because heterozygous embryos harboring the two knockout alleles $\left(\right.$ Six $1^{+/-} /$Six $4^{+/-}$, denoted as Six $\left.1 / 4^{+/ E G F P}\right)$ did not exhibit obvious anomalies in DRG development (Figure 3A-C), we used them to examine Six1 expression by monitoring green fluorescence. EGFP-positive soma in Six1/4 1 EGFP embryos was mostly positive for ISL1/2 immunofluorescence (Figure 3D), indicating activation of the Six1 locus in the majority of ISL1/2-positive neurons at some point during differentiation, because EGFP protein can reside in cells for a longer period than SIX1 protein. These observations point to the potential role of SIX1 in differentiation of NCC into DRG neurons.

The DRG of double-knockout embryos $\left(\mathrm{Six}^{-/-} / \mathrm{Six} \mathrm{H}^{-/-}\right.$, denoted as Six $1 / 4^{E G F P / E G F P}$ ) were smaller and flat mediolaterally compared to those of the wild type and Six $1 / 4^{+/ E G F P}$ at E11.5 (Figure 3E,F). In addition, ISL1/2-positive neurons were dispersed and emigrated ventrally compared with those in Six1/4 $4^{+/ E G F P}$ (Figure 3E,F). Furthermore, ISL1/2and SOX10-double-positive cells, which are reminiscent of immature NCCs, were frequently observed $(n=19$, Figure $3 \mathrm{~F}$ ), whereas such cells were rarely recognized in wild type and Six1/4 $4^{+/ E G F P}$ (Figure 3E). Finally, the lumbar DRG was found to fuse later in the development of Six1/4 EGFP/EGFP (Figure 3G,H). Considered together with the lack of significant developmental anomalies in DRG in Six1 and Six4 single-knockout embryos [50,58], these findings suggest mutually compensatory roles for SIX1 and SIX4 in the differentiation and migration of DRG cells and gangliogenesis.

The axonal bundle at the dorsal root entry zone (DREZ) [59] was also positive for EGFP in Six $1 / 4^{+/ E G F P}$ at E11.5 (arrows in Figure 3I,K). This was owing to intracellular diffusion of the long-lasting EGFP protein, indicating that the sensory afferents originated from SIX1-positive neurons in DRG. Surprisingly, EGFP- and ISL1/2-doublepositive cells were noted inside the spinal cord near the DREZ of Six1/4 EGFP/EGFP $(\mathrm{n}=19$, Figure 3J,L), whereas these cells were hardly observed in $\operatorname{Six} 1 / 4^{+/ E G F P}(\mathrm{n}=17$, Figure 3I,K). The EGFP- and ISL1/2-double-positive cells in Six1/4 ${ }^{E G F P / E G F P}$ also showed immunofluorescence signal for NTRK3 $(\operatorname{TrkC})(\mathrm{n}=6$, Figure $3 \mathrm{~N}, \mathrm{P})$, a marker of proprioceptive neurons of the DRG [60]. By contrast, the NTRK3 signal was observed only in the axonal bundle of DREZ in the spinal cords of $\operatorname{Six} 1 / 4^{+/ E G F P}(\mathrm{n}=5$, Figure $3 \mathrm{M}, \mathrm{O})$. These findings suggest the novel roles for SIX1 and SIX4 in the development of DRG and preclusion of intramedullary sensory neurons.

\section{SIX1 prevents the appearance of sensory neurons in mouse spinal cord}

To define the properties of intramedullary EGFP-positive cells in Six $1 / 4^{E G F P / E G F P}$, we first assessed the projection of neurites. The retrograde tracer rhodamine-dextran was injected into a region outside the spinal cord in E11.5 embryos and subsequently observed in EGFP-positive soma in the spinal cords of Six1/4 EGFP/EGFP $(\mathrm{n}=3$, Figure 4B). By contrast, the tracer was noted only in the sensory axon bundle at the DREZ of Six1/4 $4^{+/ E G F P}(\mathrm{n}=3$, Figure $4 \mathrm{~A})$. These results indicate that these EGFP-positive cells in Six $1 / 4^{E G F P / E G F P}$ extend their processes outside the spinal cord. In the thoracolumbar region of wild-type mouse spinal cord, only somatic motor neurons and preganglionic motor column cells with projections to the sympathetic ganglia send axons from the inside of the spinal cord to the outside, through the ventral root [61]. The atypical projection of the intramedullary EGFP-positive cells of Six1/4 ${ }^{E G F P / E G F P}$ embryos suggests resemblance to the intramedullary sensory neurons, RB cells, of anamniotes.

Xenopus RB cells are Tlx3-positive (see Figure 2). The majority of intramedullary EGFP-positive cells in Six1/ $4^{E G F P / E G F P}$ were positive for TLX3 $(\mathrm{n}=6$, Figure 4D). The DRG neurons and subsets of differentiated interneurons in the dorsal spinal cord were also TLX3positive, as reported previously [62] (Figure 4C), however, these cells appeared normal in Six1/4 EGFP/EGFP $(n=6$, Figure $4 C, D)$. The transcript of a Shaker-like potassium 

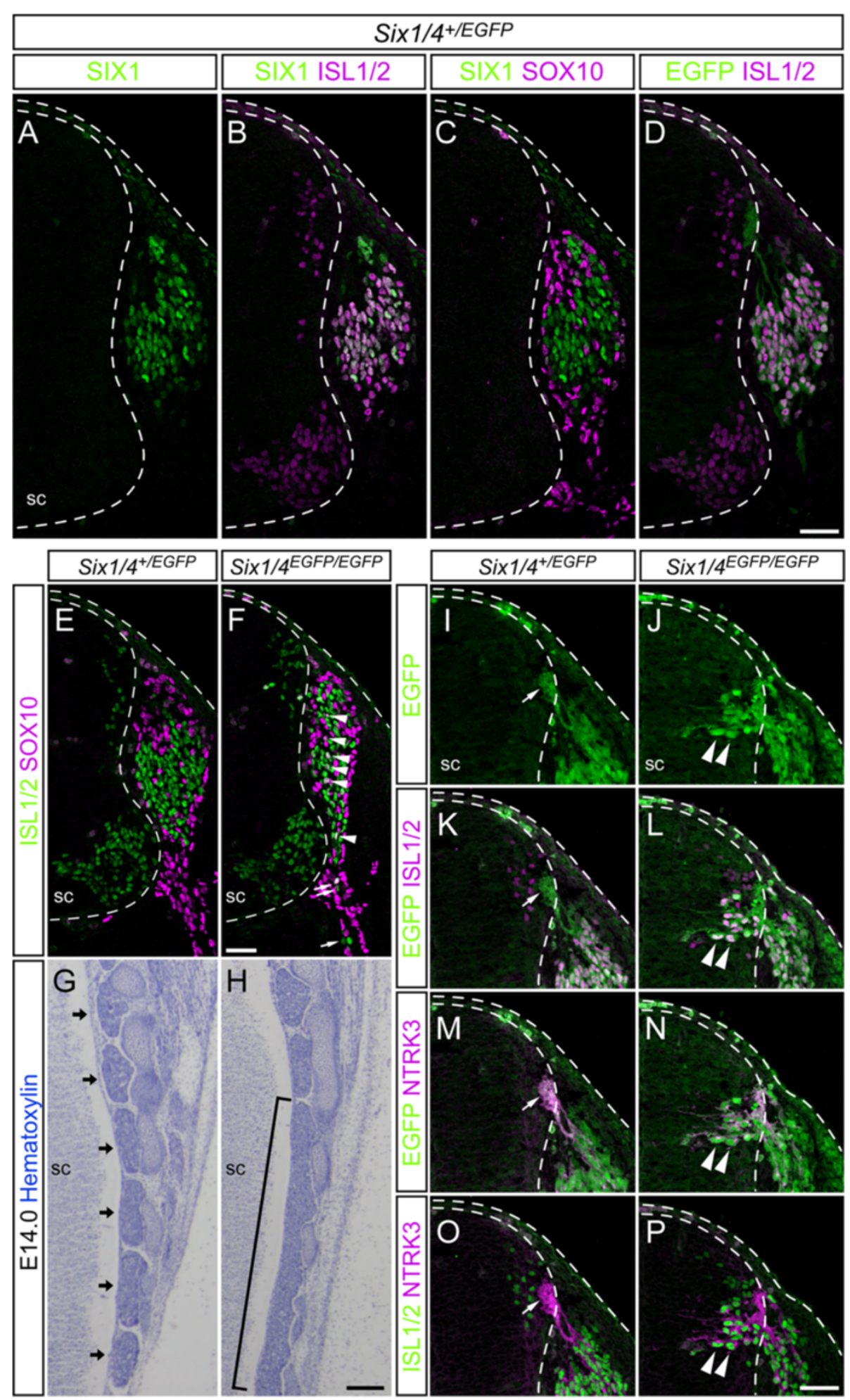

Figure 3 (See legend on next page.) 
(See figure on previous page.)

Figure 3 SIX1 is crucial during mouse dorsal root ganglia development. (A-D) Immunofluorescence of SIX1 (green), neuronal marker ISL1/2 (magenta) and glial marker SOX10 (magenta) in dorsal root ganglia (DRG) of embryonic day (E) 11.5 Six $1 / 4^{+/ E G F P}$ embryos, in which the Six 1-locus directs the expression of enhanced GFP (EGFP; green). (E-P) Abnormalities in Six 1/4 ${ }^{E G F P / E G F P ~ D R G . ~(E, F) ~ A r r o w h e a d s: ~ I S L 1 / 2 ~(g r e e n)-~ a n d ~ S O X 10 ~}$ (magenta)-double-positive cells; arrows: ventrally located ISL1/2-positive cells (F), which were never observed in Six1/4 ${ }^{+/ E G F P}$ at E11.5 (E). (G,H) Coronal sections of lumbar region at E14.0 (top: rostral side). DRG are fused over several segments in Six $1 / 4^{E G F P / E G F P}$ embryos (square bracket in $\mathbf{H}$ ), but segmented in Six1/4 /EGFP (arrows in G). (I-P) Transverse sections of dorsal spinal cords (sC) at E11.5. Arrowheads: intramedullary EGFP (green)-, ISL1/2 (magenta)- and NTRK3 (magenta)-triple-positive cells only in Six $1 / 4^{\text {EGFP/EGFP }}$; arrows: EGFP-positive afferents at the dorsal root entry zone. Dashed lines demarcate the position of ectoderm and sc. Scale bars: $200 \mu \mathrm{m}(\mathbf{G}, \mathbf{H})$ and $50 \mu \mathrm{m}$ (A-F,I-P).

channel Kcna1 (Kv1.1) was detected previously in Xenopus RB cells [63], and we confirmed the protein localization of Kcna1 in RB cells by immunohistochemical analysis (Additional file 2B). In E11.5 Six $1 / 4^{E G F P /}$ EGFP embryos, a subset of intramedullary EGFP-positive cells was positive for KCNA1 ( $\mathrm{n}=3$, Figure 4F), although no such cells were observed in the dorsal spinal cord of Six $1 / 4^{+/ E G F P}$ embryos (Figure 4E). Runt-related transcription factors, Runx1 and Runx3, are expressed in Xenopus RB cells and Runx1 is critical for the development of RB cells $[64,65]$. The majority of intramedullary EGFP-positive cells in Six $1 / 4^{E G F P / E G F P}$ were positive for both proteins $(n=3$, Figure $4 \mathrm{H}$; Additional file 4A), although no such cells were recognized in Six1/ $4^{+/ E G F P}$ spinal cord $(\mathrm{n}=5$, Figure $4 \mathrm{G})$. RB cells are distributed in a non-segmental manner $[8,66]$, whereas DRG show segmental and symmetrical organization along the body axis. The intramedullary EGFP-positive cells of Six $1 / 4^{E G F P / E G F P}$ never showed any distinguishable segmental arrangements (Figure 4I,J). Considered together, these findings suggest that intramedullary EGFP-positive cells have substantial common features with the amphibian RB cells.

The sensory neurons in DRG originate from the NCC. Next, we examined whether the EGFP-positive cells in the spinal cord of Six $1 / 4^{E G F P / E G F P}$ originate from NCC by employing a genetic strategy to label NCC lineage. By crossing $\mathrm{PO}$-Cre mice, in which Cre recombinase is expressed in tissues derived from NCCs (PO-Cre) [67], with a transgenic mouse line harboring CAG-loxP-STOP-loxP$m R F P 1$ cassette (CAG-lxl-mRFP1), the neural crest lineage can be visualized by the red fluorescence of monomeric RFP (mRFP). Virtually all EGFP-positive intramedullary cells in the Six1/4 ${ }^{E G F P / E G F P} ; P 0-C r e ; C A G-l x l-m R F P 1$ embryos were labeled with $\mathrm{mRFP} 1$, indicating that they originated from the neural crest $(n=3$, Figure $4 K)$.

In the mouse trunk, SIX1 and SIX4 are expressed in somites and the mesenchyme $[40,50]$ in addition to the DRG. To determine whether the emergence of intramedullary EGFP-positive cells in Six $1 / 4^{E G F P / E G F P}$ embryos was caused by loss of functions of SIX1 and SIX4 in NCCs, we restored the expression of SIX1 only in NCC derivatives. For this purpose, we generated a transgenic mouse line harboring
CAG-loxP-STOP-loxP-Six1 cassette (CAG-lxl-Six1) and crossed it with $\mathrm{PO}$-Cre mice. The number of EGFP- and ISL1/2-double-positive cells was markedly reduced in the spinal cords of Six $1 / 4^{E G F P / E G F P} ; P 0-C r e ; C A G-l x l$-Six 1 embryos $(n=4$, Figure $4 \mathrm{~L})$. The abnormal morphology and organization of Six $1 / 4^{\text {EGFP/EGFP }}$ DRG were also rescued and the DRG resembled those of Six $1 / 4^{+/ E G F P}$ (Figure 4L, compare with Figure 3). The number of EGFP- and ISL1/ 2-double-positive cells in the spinal cord at the level of somites 21 to 26 was significantly higher in Six $1 / 4^{E G F P / E G F P}$ embryos $(1,097.5 \pm 113.6$ cells/embryo, $\mathrm{n}=4, p=0.00007)$, compared to Six $1 / 4^{+/ E G F P}$ embryos $(4.0 \pm 1.3$ cells/embryo, $\mathrm{n}=4$; Figure $4 \mathrm{M})$. NCC lineage-specific restoration of SIX1 expression markedly reduced the number of these cells to $309.8 \pm 33.1$ cells/embryo in Six $1 / 4^{E G F P / E G F P} ; P 0-C r e ; C A G-$ $l x l$-Six 1 mice $(\mathrm{n}=4, p=0.0006$; Figure $4 \mathrm{M})$. These results suggest that the cell-autonomous function of SIX1 in the NCC primarily suppresses the developmental program responsible for the generation of intramedullary sensory neuron-like cells during mouse development.

Taken together, these findings highlight the importance of SIX1 and SIX4 in NCC-lineage in the formation of DRG and preclusion of intramedullary sensory neuronlike cells in mice (Figure $4 \mathrm{~N}$ ).

\section{Medial migration of neural crest cells results in intramedullary sensory neuron-like cells}

To determine the mechanism and source of intramedullary sensory neuron-like cells, we examined their ontogeny. EGFP-positive intramedullary cells were first observed at E10.5 at the level of the thoracolumbar region in Six $1 / 4^{E G F P / E G F P}$ embryos, and their number reached peak level at E11.5 (Figure 5A). The basal lamina marked with laminin-staining was often interrupted by the presence of EGFP- and ISL1/2-double-positive cells at the DREZ in E11 to $11.5 \mathrm{Six} 1 / 4^{E G F P / E G F P}$ embryos $(n=8$, Figure $6 \mathrm{E}-\mathrm{H})$, although the gaps of basal lamina were normally occupied by axons originating from DRG neurons in Six1/4 ${ }^{+/ E G F P}(\mathrm{n}=17$, Figure 6A-D). Time-lapse live imaging analysis of slice cultures of the E11 Six $1 / 4^{E G F P / E G F P}$ embryos at lumbar level indicated that EGFP-positive cells migrated medially toward the spinal cord and finally into it $(n=5$, Figure 6I; Additional 


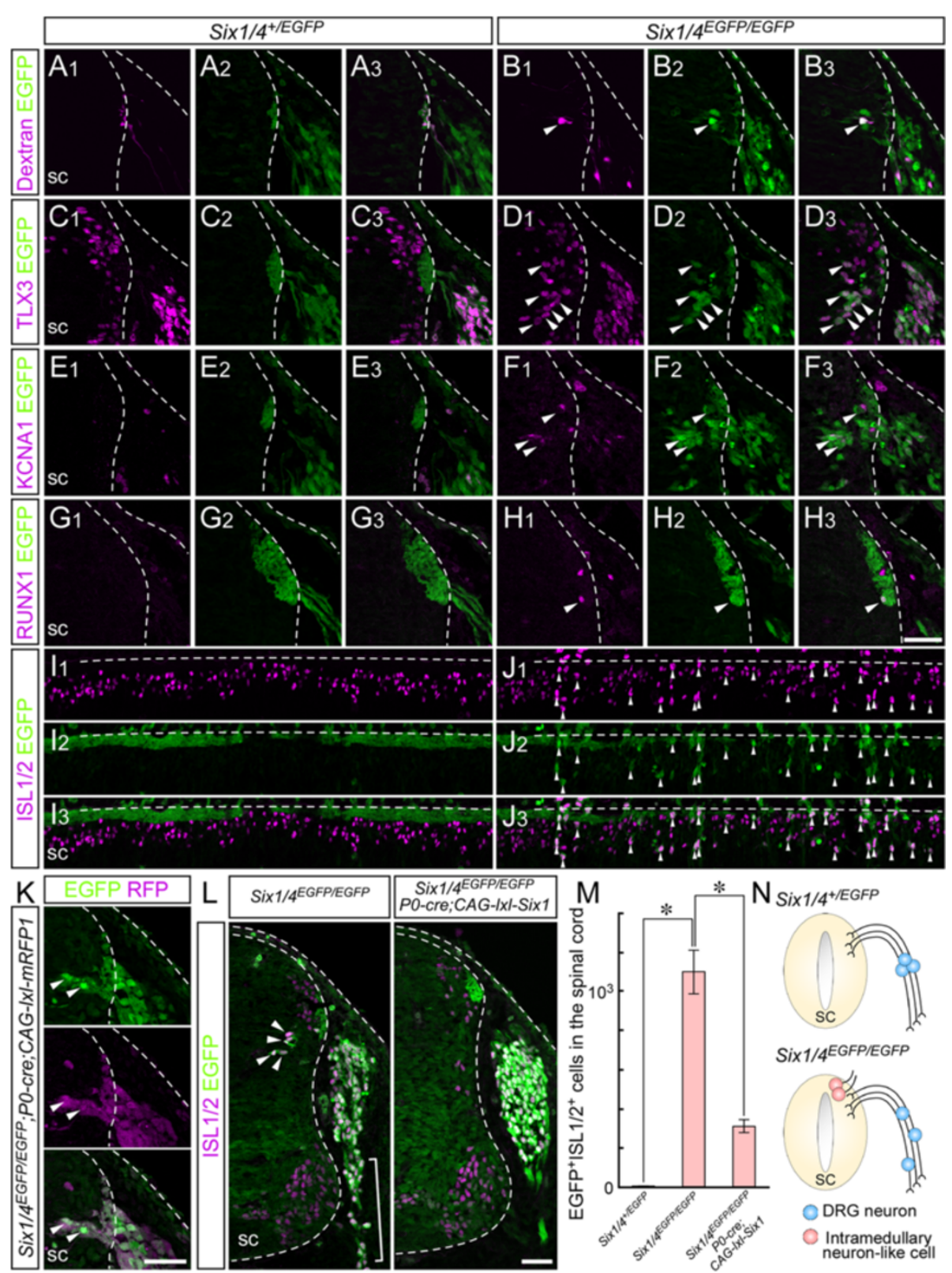

Figure 4 Appearance of intramedullary sensory neuron-like cells in Six $1 / 4^{\text {EGFP/EGFP }}$ mice. (A-H) Magenta represents rhodamine-dextran injected outside the spinal cord (SC) (A,B), TLX3 (C,D), KCNA1 (E,F), RUNX1 (G,H) and (I,J) ISL1/2, which are detected in intramedullary enhanced GFP (EGFP)positive cells (green) in Six1/4 ${ }^{\text {EFP/EGFP }}$ spinal cord. Arrowheads: double-positive cells. (K) Intramedullary EGFP-positive cells (green) are labeled with neural crest cell (NCC) lineage-specific fluorescence of monomeric RFP (magenta). (L) EGFP (green)- and ISL1/2 (magenta)-double-positive intramedullary cells disappear with NCC-specific restoration of SIX1. (M) Number of EGFP- and ISL1/2-double-positive cells in the spinal cord at the level of somite 21 to 26. (N) Schematic representation of dorsal root ganglion (DRG) neurons (blue) and intramedullary neuron-like cells (pink) in Six $1 / 4^{+/ E G F P}$ and Six $/ / 4^{\text {EGFP/EGFP }}$ $\mathbf{A}-\mathbf{F}$ and $\mathbf{I}-\mathbf{L}$ are on embryonic day (E)11.5; $\mathbf{G}$ and $\mathbf{H}$ are on $\mathbf{E} 12$. A-H, $\mathbf{K}$ and $\mathbf{L}$ are transverse sections (top: dorsal side); $\mathbf{I}$ and $\mathbf{J}$ are coronal sections (top: lateral side). Data are mean \pm standard error of the mean. ${ }^{*} p<0.001$. Dashed lines demarcate the position of ectoderm and sc. Scale bars: $50 \mu \mathrm{m}$.

file 5). Taken together with the results of labeling and rescue analysis using $\mathrm{PO}-\mathrm{Cre}$ (Figure $4 \mathrm{~K}-\mathrm{M}$ ), medial migration of NCCs into the spinal cord seems a plausible mechanism for the emergence of intramedullary EGFP-positive cells in Six $1 / 4^{\text {EGFP/EGFP }}$.

\section{Lack of dorsal root entry zone disruption before} emergence of intramedullary sensory neuron-like cells To explore the mechanism underlying the emergence of sensory neuron-like cells in the mouse spinal cord, we examined the boundary structure between the CNS and 

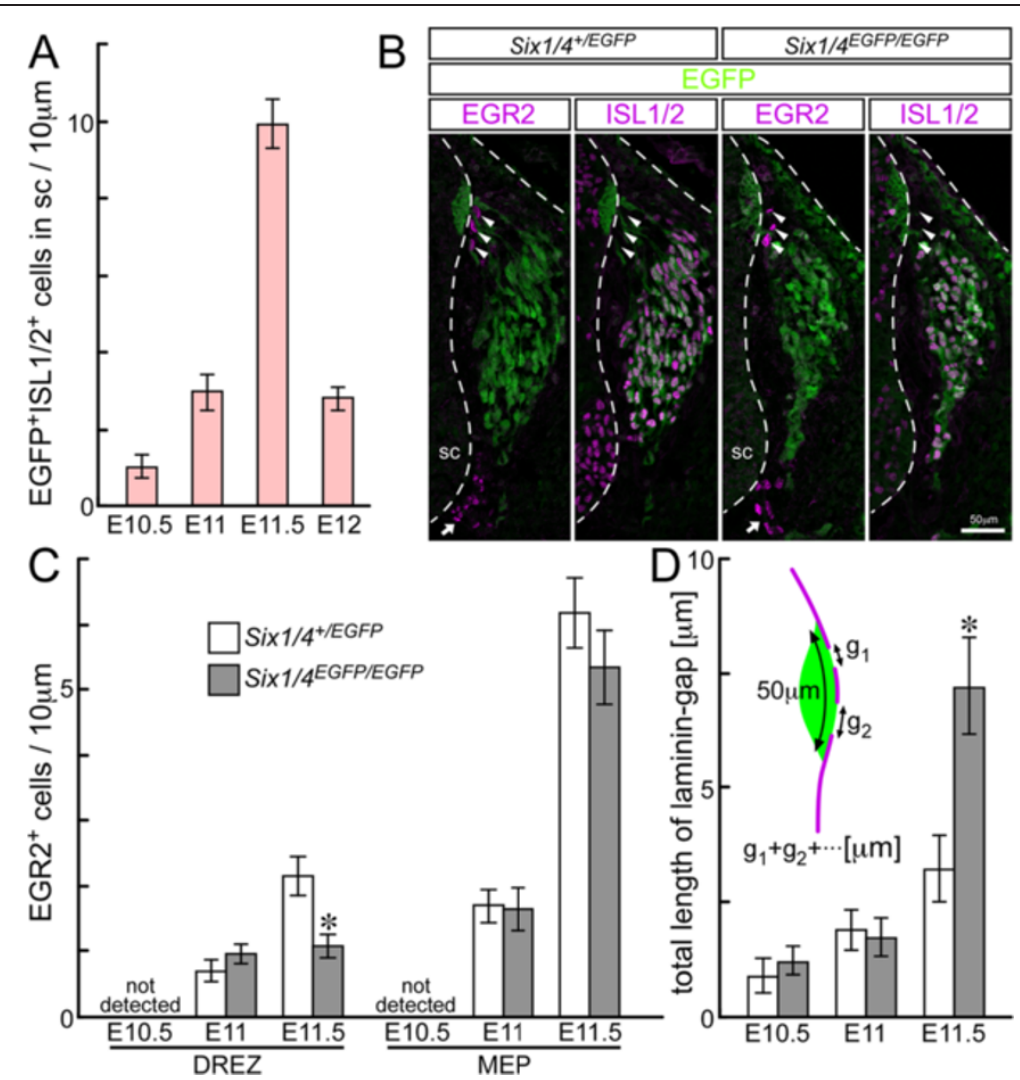

Figure 5 Appearance of intramedullary sensory neuron-like cells in Six $1 / 4^{\text {EGFP/EGFP }}$ mice precedes disorganization of the dorsal root entry zone. (A) Number of enhanced GFP (EGFP)- and ISL1/2-double-positive cells in $10 \mu \mathrm{m}$ sections of embryonic day (E) 10.5 to 12 Six $1 / 4^{E G F P /}$ EGFP thoracolumbar spinal cord. (B) EGR2-positive cells (magenta) at the dorsal root entry zone (DREZ) (arrowheads) and at the motor exit point

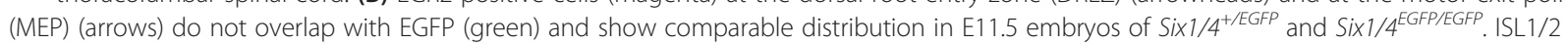
(magenta) marks dorsal root ganglion neurons. (C) Number of EGR2-positive cells in $10 \mu \mathrm{m}$ sections of E10.5 to E11.5 at the DREZ and MEP of Six1/4 +/EGFP and Six1/4 EGFP/EGFP. (D) Total length of laminin gaps in 50- $\mathrm{um}$ length of basal lamina covering the primordium of the dorsal funiculus. In all measurements, at least five sections from three embryos were used per genotype. Data are mean \pm standard error of the mean. ${ }^{*} p<0.005$. Dashed lines demarcate the position of ectoderm and spinal cord (sc). Scale bar: $50 \mu \mathrm{m}$.

peripheral nervous system (PNS) on the surface of the spinal cord.

Boundary cap $(\mathrm{BC})$ cells are known to maintain the integrity of the boundary structure between the CNS and PNS. Specifically, BC cells prevent the emigration of motor neurons at the ventral part of the spinal cord (the MEP) and of glial cells to the periphery at the DREZ $[68,69]$. BC cells can be identified by the expression of EGR2 (KROX20) [70,71]. EGR2-positive nuclei did not overlap with EGFP fluorescence in either $\operatorname{Six} 1 / 4^{+/ E G F P}$ or Six $1 / 4^{E G F P / E G F P}$ embryos at E11.5 (Figure 5B), and the distribution of EGR2-positive cells located at the DREZ and MEP was not apparently different between $\operatorname{Six} 1 / 4^{+/ E G F P}$ and Six $1 / 4^{\text {EGFP/EGFP }}$ (arrowheads and arrows in Figure 5B, respectively). At E10.5, no EGR2-positive cells were observed at the DREZ (assayed in 14 embryos with 30 to 35 pairs of somites, Figure 5C), although they were observed in the cervical region [72]. EGR2-positive cells were first detected at the level of the thoracolumbar region at E11 $(n=5$, Figure 5C) after the appearance of intramedullary EGFP-positive cells at E10.5. At E11, the numbers of EGR2-positive cells at both the DREZ and MEP were not different between $\operatorname{Six} 1 / 4^{+/ E G F P}$ and Six1/4 ${ }^{E G F P / E G F P}$. At E11.5, the number of EGR2-positive cells at the DREZ of Six $1 / 4^{\text {EGFP/EGFP }}(1.1 \pm 0.2$ cells $/ 10 \mu \mathrm{m}, \mathrm{n}=5, p=0.004)$ was approximately half that of Sixl/4 /EGFP $(2.20 .3$ cells/ $10 \mu \mathrm{m}, \mathrm{n}=6$ ), although the number was similar in MEP. These findings indicate that the emergence of intramedullary EGFP-positive cells at the level of the thoracolumbar region precedes that of BC cells in Six $1 / 4^{E G F P / E G F P}$ embryos. At E11.5, when intramedullary EGFP-positive cells were largest in number in Six1/4 EGFP/EGFP embryos, the number of BC cells at the DREZ of Six1/4 $4^{E G F P / E G F P}$ was smaller compared with that of Six $1 / 4^{+/ E G F P}$.

We also investigated the distribution of laminin, a major component of the basal lamina, to evaluate the integrity of the boundary structure between the CNS and PNS at the DREZ. Gaps in the laminin layer usually mark the site of 


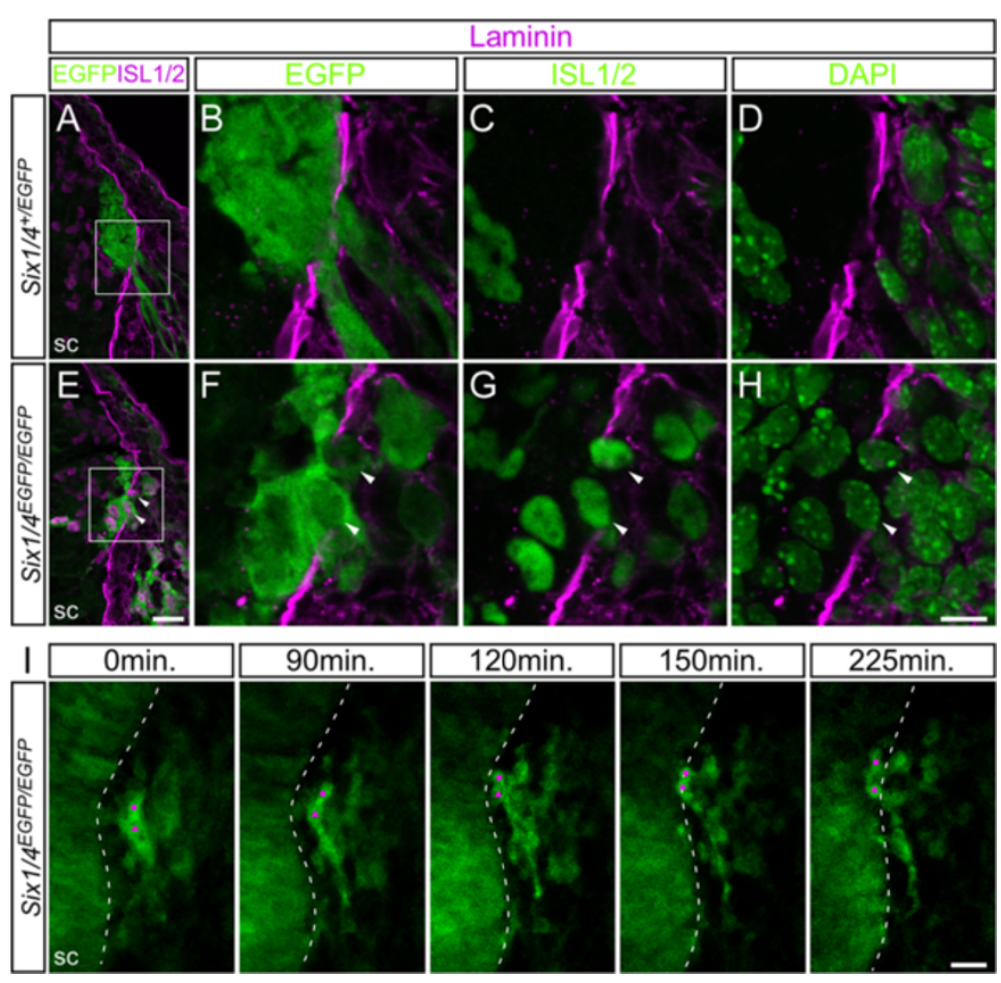

Figure 6 Medial migration of intramedullary sensory neuron-like cells in Six $1 / 4^{\text {EGFP/EGFP }}$ mice. (A-H) Abnormalities in the Six $1 / 4^{\text {EGFP/EGFP }}$ dorsal root entry zone (DREZ). (B-D) and (F-H) show close-up of the DREZ (indicated with rectangles) in Six $1 / 4^{+/ E G F P}$ (A) and Six $1 / 4^{E G F P / E G F P}$ (E). ISL1/2 (magenta/green)- and enhanced GFP (EGFP; green)-double positive cells (arrowheads) are located across the basal lamina, which is demarcated by the immunofluorescence signal of laminin (magenta). The position of nuclei is visualized with DAPI (green). (I) Time-lapse imaging of EGFP-positive cells on the slice culture of embryonic day 11 Six $1 / 4^{E G F P / E G F P}$ lumbar region. Top line shows elapsed time of observation. See also Additional file 5. Dashed lines demarcate the position of the spinal cord (sc). Scale bars: $25 \mu \mathrm{m}(\mathbf{A}, \mathbf{E}, \mathbf{I})$ and $10 \mu \mathrm{m}(\mathbf{B}-\mathbf{D}, \mathbf{F}-\mathbf{H})$.

penetration of dorsal roots from DRG neurons into the spinal cord (Figure 6A-D) [73]. In Six1/4 EGFP/EGFP embryos, intramedullary EGFP-positive cells could originate from the cells that pass through the gaps and invade the spinal cord in the presence of possible disruption of the border. Gaps in the immunofluorescence signal of laminin were observed in the DREZ of both $\operatorname{Six} 1 / 4^{+/ E G F P}$ and Six $1 /$ $4^{E G F P / E G F P}$ embryos (Figure 5D). At E11.5, the total length of laminin gaps in 50- $\mu \mathrm{m}$ length of basal lamina covering the DREZ was significantly greater in Six $1 / 4^{\text {EGFP/EGFP }}(7.2 \pm$ $1.1 \mu \mathrm{m}, \mathrm{n}=4, p=0.004)$ than $\operatorname{Six} 1 / 4^{+/ E G F P}(3.2 \pm 0.7 \mu \mathrm{m}$, $\mathrm{n}=4$ ). The difference was caused by the larger number of laminin gaps rather than longer individual gaps in the

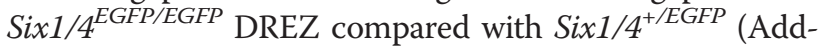
itional file 6). However, the total length of laminin gaps was comparable in the DREZ of Six $1 / 4^{+/ E G F P}$ and Sixl/ $4^{E G F P / E G F P}$ at earlier developmental stages of E10.5 and E11, at which intramedullary EGFP-positive cells were already present. These findings suggest that the number of laminin gaps at the DREZ increased after the emergence of intramedullary EGFP-positive cells in Six $1 / 4^{E G F P / E G F P}$ embryos.
Considered together, the above findings suggest no apparent change in the boundary structure at the DREZ before the emergence of intramedullary sensory neuron-like cells in Six $1 / 4^{E G F P / E G F P}$ embryos, and that the number of $\mathrm{BC}$ cells decreased while that of laminin gaps increased after the emergence of intramedullary cells. Thus, the emergence of sensory neuron-like cells in the spinal cord of Six $1 / 4^{E G F P / E G F P}$ embryos could be due to translocation of NCCs into the spinal cord, and the most probable mechanism for such translocation is a change in the intrinsic properties of NCCs.

\section{Mouse Six 1 enhancer is activated earlier than Xenopus enhancer in Rohon-Beard cells}

The above findings demonstrated the role of Six 1 in the transition of trunk sensory system from RB cells to DRG neurons in Xenopus and in DRG formation and preclusion of intramedullary sensory neuron-like cells during mouse development. Thus, Six genes seem to be involved in the evolutionary disappearance of intramedullary sensory neurons, such as RB cells. In Xenopus, Six1 expression begins in $\mathrm{RB}$ cells preceding their apoptotic death during the 
transition from RB cells to DRG (Figure 1). By comparison, the expression of SIX1 persists from the beginning of mouse DRG development (Figure 3). The expression profiles of Six1 in Xenopus and mouse suggest that the onset of Six1 expression during the entire developmental process of trunk sensory neurons could be different in these species, and that such difference could be the genetic basis of the disappearance of RB cells and exclusive development of DRG. However, the developmental time scale is not the same in Xenopus and mouse, because both species possess their own unique developmental processes acquired after the amphibian-amniotes divergence about 350 million years ago. Therefore, it is difficult to directly compare the timing of onset of Six1 expression between Xenopus and mouse. Accordingly, we focused on a conserved Six1 enhancer (Six1-8) solely responsible for the expression of the gene in DRG neurons [74], and evaluated the timing of activation of mouse (mSix1-8) and Xenopus (xSix1-8) enhancers under the same environment. We generated transgenic Xenopus in which mSix18 or xSix1-8 drives EGFP expression to monitor enhancer activity in vivo [75]. In the trunk of mouse embryos, mSix1-8 activated the transcription in DRG later than E10 [74]. Surprisingly, the enhancer activity of mSix1-8 was observed in Xenopus RB cells at St. 25/26 (75.9 $\pm 3.8 \%$ RB cells, $\mathrm{n}=5)$, before the endogenous expression of Six1, and at St. 41/42 (87.1 $\pm 1.6 \%$ RB cells, $n=12$; Figure $7 \mathrm{~B})$. By contrast, the activity of xSix1-8 was observed only in a minor proportion of RB cells at St. 25/26 (12.8 $\pm 3.4 \%$ RB cells, $\mathrm{n}=7)$, but became prominent at St. $41 / 42(83.9 \pm$ $2.6 \% \mathrm{RB}$ cells, $\mathrm{n}=12$; Figure $7 \mathrm{~A}$ ), just with the appearance of endogenous expression of Six1 (Figure 1). Both enhancers showed activity in DRG at St. 49 (Figure 7A,B). These results provide strong support to our notion that Six1 expression appears earlier in trunk sensory neurons of mouse than Xenopus (Figure 7C). More importantly, the earlier expression is likely mediated by modification of a single enhancer that shares sequence similarity between Xenopus and mouse.

\section{Discussion}

In this study, we found that Six1 is a key regulator of transition from intramedullary sensory neurons (RB cells) to extramedullary sensory neurons (DRG neurons) during Xenopus development (Figures 1 and 2); SIX1 precludes the appearance of intramedullary sensory neurons in mouse spinal cord by preventing NCCs migrating into the medulla (Figures 3, 4, 5 and 6); and the timing of Six1 expression in sensory neurons could be altered by changing enhancer sequences (Figure 7).

Previous studies have described the roles of Six1 in proliferation and neuronal differentiation in the sensory systems $[41,42,48]$. The present study describes Six1 as a key regulator of apoptosis during the process of disappearance of Xenopus RB cells and assigning proper location of mouse sensory neurons. Because cdk 5 is involved both in apoptosis and positioning of RB cells in zebrafish [29,76], the differential functions of Six1 might be elaborated by such molecules. It is possible that the precocious disappearance of RB cells in six1-overexpressed Xenopus embryos is caused by reasons other than apoptosis. Defects in the medial migration are expected to reduce the number of RB cells incorporated in the dorsal spinal cord of Xenopus, analogous to mouse development in which the medial migration of NCCs leading to the emergence of intramedullary sensory neuron is precluded by Six genes. Identifying the mechanism of disappearance of RB cells might produce further evidence to understand the evolution of sensory neuron architecture.

Surprisingly, sensory neuron-like cells appeared in the spinal cord of Six $1 / 4^{E G F P / E G F P}$, though it is unclear whether they are functional or not. What is the identity of such cells and what does their appearance imply? Intramedullary EGFP-positive cells disappeared by E12.5, probably due to apoptotic cell death (Additional file 4B), which might be induced by inappropriate environment for survival. The disappearance does not allow us to characterize the functional features of such cells as sensory neurons. The sporadic presence of such cells has been reported in amniotes, including reptiles [6] and human embryos [77,78]. Intramedullary neurons in human embryos are considered to be homologous to RB cells, because they share anatomical characteristics with amphibian RB cells [77]. Such cells are located in the region where dorsal root fibers enter the spinal cord in human, reminiscent of the position of emergence of intramedullary sensory neuron-like cells in Six $1 / 4^{E G F P / E G F P}$ mice. The facts that intramedullary EGFP-positive cells in Six1/4 EGFP/EGFP express NTRK3, TLX3, KCNA1, RUNX1 and RUNX3; possess neurites leaving the spinal cord; and are distributed in a non-segmental manner indicate that they share certain properties with the RB cells. It has been proposed that NCCs and RB cells evolutionarily share a common origin [79]. There are a couple of molecular evidences supporting this scenario: Notch/Delta signaling is involved in segregating the two fates [24,25], Prdm1 has a role to specify both [28], and Runx1 is required for the differentiation of both RB cells and subtype of DRG neurons $[64,80]$. That intramedullary cells in mouse share some features with RB cells and are derived from NCCs, similar to DRG neurons, suggests common origin of intra- and extramedullary sensory neurons. Despite the fact that both DRG neurons and intramedullary EGFP-positive cells are derived from NCCs, they seem to follow segmental and non-segmental arrangement in Six1/ $4^{E G F P / E G F P}$ embryos, respectively. Segmental arrangement of DRG is determined by NCC-somite interactions $[81,82]$. Intramedullary EGFP-positive cells might be 


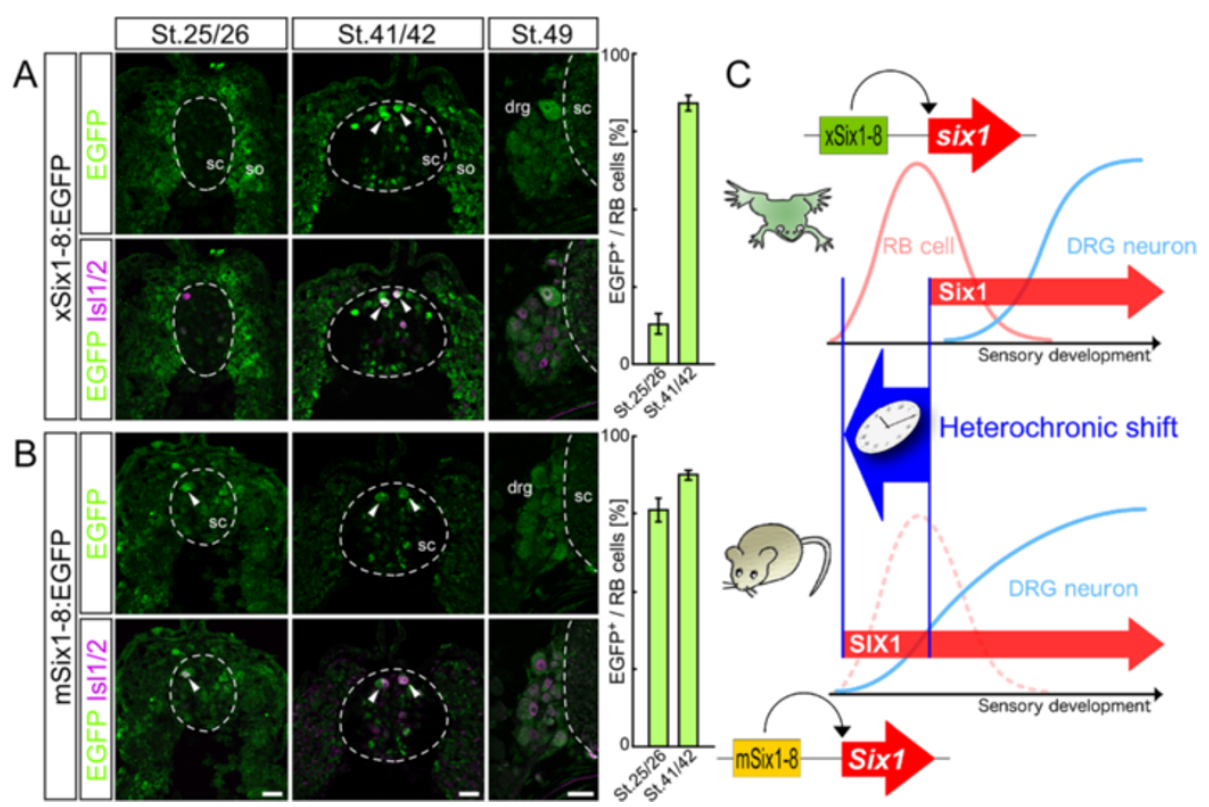

Figure 7 Mouse Six 1 enhancer for dorsal root ganglion neurons directs expression in Rohon-Beard cells earlier than Xenopus enhancer. (A) Xenopus enhancer directed the expression of enhanced GFP (EGFP; green) in Rohon-Beard (RB) cells (magenta, labeled by IsI1/2) not at Stages (St.) 25/26, but at St. 41/42, and in dorsal root ganglion (DRG) neurons at St. 49. (B) Mouse enhancer directed expression of EGFP in RB cells at St. 25/26 and 41/42, and in DRG neurons at St. 49. For $\mathbf{A}$ and $\mathbf{B}$, bar graphs show the percentage of EGFP-positive RB cells in $250 \mu m$ of the thoracic level. Data are mean \pm standard error of the mean. Arrowheads: EGFP- and Is|1/2-double-positive RB cells; dashed lines demarcate the position of the spinal cord (sc); so, somite; drg, dorsal root ganglia. Scale bars: $25 \mu \mathrm{m}$. (C) Schematic representation of timing of Six 1 expression in Xenopus and mouse. Xenopus six 1 enhancer for sensory neurons (xSix1-8) directs the expression of Six 1 (red arrow) to alter the sensory system from RB cells (pink line) to DRG neurons (blue line). In mouse, Six 1 enhancer (mSix1-8) mediates SIX1 expression earlier during trunk sensory development. This altered timing of SIX1 expression inhibits the development of intramedullary sensory cells and promotes DRG neurogenesis.

relieved from such signaling because they are physically isolated from the influence of somites by the basal lamina. One of the key components of NCC-somite interactions is neuropilin (NRP)/semaphorin signaling. NRP1 and NRP2 are expressed in NCCs and play essential roles in segmental formation of DRG and segmental migration of NCCs, respectively [83-85]. NRP1, but not NRP2, was expressed in intramedullary EGFP-positive cells of $\operatorname{Six} 1 / 4^{E G F P / E G F P}$ (Additional file 4C), although the cells are derived from NCCs. Because genetic ablation of NRP2 results in disorganization of segmental migration of NCCs [85], nonsegmental arrangement of intramedullary EGFP-positive cells in Six $1 / 4^{E G F P / E G F P}$ might be due to the lack of NRP2 expression rather than the physical isolation mentioned above. Interestingly, Nrp1, but not Nrp2, is also expressed inside Xenopus spinal cord [86], where RB cells exist, suggesting that the combined expression of Nrps is a potential molecular basis for the non-segmental arrangement of intramedullary sensory neurons.

How do ectopic intramedullary sensory neurons appear in the Six $1 / 4^{E G F P / E G F P}$ embryos? Our analysis demonstrated that the incorporation of migrating NCCs into the spinal cord is the most plausible scenario for the presence of such cells. Davidson and Keller [27] showed that frog dorsal neural tube is remodeled by medial migration and radial intercalation of lateral neural plate, including $\mathrm{RB}$ cells, which appear in the lateral edge of the neural plate before neural tube formation. In other words, already-specified RB cells segregate from the border and migrate medially to settle in the dorsal neural tube. A similar morphological event is observed in fish development $[28,29]$. The intramedullary EGFPpositive cells in Six $1 / 4^{E G F P / E G F P}$ embryos show medial migration into the spinal cord from the outside. Of course, one cannot completely exclude the involvement of other mechanisms in the emergence of intramedullary EGFP-positive cells in Six $1 / 4^{E G F P / E G F P}$ in addition to the medial migration of NCCs. Abnormalities in the structure that separates the CNS and PNS at the DREZ could be one such mechanism involved in the process of migration of NCCs into the spinal cord. We observed fewer BC cells and larger number of laminin gaps at the DREZ at E11.5 in Six $1 / 4^{E G F P / E G F P}$ compared with Six $1 / 4^{+/ E G F P}$. However, the fact that intramedullary EGFP-positive cells were already present at E10.5 suggests that defects in the boundary structure is not the primary reason for the appearance of intramedullary sensory neuron-like cells in Six $1 / 4^{\text {EGFP/EGFP }}$ embryos.

Our data suggest that Six 1 is also involved in the evolution of extramedullary sensory neurons or the DRG system. 
Acquisition of new expression domains of Six 1 in the dorsal spinal cord or in the NCC lineage may have contributed to the establishment of the DRG system. The mouse Six1 enhancer for DRG neurons exhibited earlier enhancer activity than Xenopus six 1 enhancer in $\mathrm{RB}$ cells and precocious overexpression of Six1 caused premature differentiation of extramedullary neurons during Xenopus development. This raises the possibility that the earlier expression of Six 1 in the dorsal neural tube, including RB cells and NCCs, was acquired at some point during the evolution from anamniotes to amniotes. This hypothesis can be tested by analyzing the activities of the corresponding enhancers from various species including reptiles and birds.

Moreover, the directive role of Six1 in generating extramedullary sensory neurons may have deeper origins. In the amphioxus embryos, Six $1 / 2$ seems to be expressed in type I epidermal sensory cells outside the spinal cord [87]; however, its expression has not been reported in Retzius bipolar cells, which are probably homologous to RB cells. Although there is controversy regarding the vertebrate cell type that is homologous to amphioxus extramedullary type I sensory cells [87], the expression of Six1 in extramedullary sensory neurons of both amphioxus and vertebrates is intriguing and suggests that Six 1 is being recruited as one of the key regulators for generating sensory neurons outside the spinal cord, despite the different evolutionary or developmental origins of the cells.

Following the concept that altered expression of developmental regulators is an important step in morphological evolution [88], evolutionary insights have been made from experimental results obtained through the manipulation of gene expression [89,90]. Recent work has elegantly demonstrated that the acquisition of a novel enhancer results in a change in gene expression, yielding morphological diversity [91]. This suggests that the upstream mechanisms acting on the enhancer could be established prior to morphological changes. Our findings suggest that changes in the enhancer sequence that caused heterochronic shift in Six1 expression in the trunk sensory precursors of the amniote ancestors could be the genetic basis for the succession from intra- to extramedullary sensory neurons, including the disappearance of RB cells (Figure 7C).

\section{Conclusions}

In the present study, we used inter-species gene manipulations to show the critical role of Six1 in switching of RB cells to DRG neurons in frog and in the establishment of the exclusive DRG system of mice, coupled with late or early onset of Six 1 expression during sensory development. Gain- and loss-of-function of Six1 was demonstrated by experimental changes in intra- versus extramedullary sensory neurons both in frogs and mice, suggesting the conserved function of Six1 in both species despite the different sensory architectures. The species-specific activities of Six 1 enhancers, which correlate with the differential onset of Six1 expression in the trunk sensory precursors, could be the genetic basis for the different sensory architecture in frogs and mice. Our findings provide a specific example of how alterations in gene expression can contribute to substantial changes in morphology during evolution.

\section{Methods}

\section{Animals}

Xenopus laevis embryos were obtained by in vitro fertilization using standard methods [92] and staged according to [93]. Six $1 / 4^{\text {EGFP/EGFP }}$ and PO-Cre mice were generated as described previously $[48,57,67]$. Transgenic mouse lines harboring CAG-loxP-STOP-loxP-mRFP1 (containing CAG promoter, floxed stop sequence, mRFP1 cDNA and rabbit $\beta$-globin polyA) or CAG-loxPSTOP-loxP-Six1 (containing CAG promoter, floxed stop sequence, cDNA coding $\mathrm{N}$-terminal flag/C-terminal myc-tagged mouse Six 1 and rabbit $\beta$-globin polyA) cassettes were generated using standard protocols and maintained by backcrossing more than 10 generations to C57BL/6. PCR was performed to verify the genotypes of offspring. Mice were housed in an environmentally controlled room. All animal experiments were carried out in a humane manner after approval of the Institutional Animal Experiment Committee of the Jichi Medical University, and in accordance with the Institutional Regulation for Animal Experiment and Fundamental Guideline for Proper Conduct of Animal Experiment and Related Activities in Academic Research Institutions under the jurisdiction of the Ministry of Education, Culture, Sports, Science and Technology of Japan.

\section{Immunofluorescence}

Immunofluorescence was performed as described previously [61] using the following primary antibodies: guinea pig anti-SIX1 [39] (1:5,000 dilution), rat anti-SIX1 [48] (1:2,000 dilution), guinea pig anti-SIX4 [48] (1:2,000 dilution), rat anti-SIX1 (1:2,000 dilution, prepared against chick Six1), mouse anti-ISL1/2 (1:150 dilution of a mixture of hybridoma supernatants, 39.4D5 and 40.2D6, Developmental Studies Hybridoma Bank, Iowa City, USA), guinea pig anti-SOX10 (1:20,000 dilution, prepared against mouse SOX10 peptides), goat anti-NTRK3 (1:1,500 dilution, R\&D Systems, Minneapolis, USA), rabbit anti-TLX3 [62] (1:10,000 dilution), rabbit antiKCNA1 (1:2,000 dilution, Alomone Labs, Jerusalem, Israel), rabbit anti-RUNX1 (1:1,000 dilution, Abcam, Cambridge, UK), rabbit anti-laminin (1:3,000 dilution, Sigma, St. Louis, USA), rabbit anti-cleaved CASP3 (1:1,000 dilution, Cell Signaling Technology, Danvers, USA) and rabbit anti-EGR2 (1:1,000 dilution, Covance, Princeton, USA and Abcam) antibodies. To visualize 
immunoreactions of primary antibodies, fluorophore (Alexa Fluor 405, 488, 546, 633 and Cy5)-labeled species-specific secondary antibodies (Molecular Probes/ Invitrogen, Carlsbad, USA and Amersham Biosciences, Amersham, UK) were used at 1:2,000 dilution. The immunofluorescent images were captured with FV1000 (Olympus, Tokyo, Japan) laser confocal microscope and electronically assigned to green or magenta channels.

\section{In situ hybridization}

Nucleotides 355 to 907 of X. laevis six1 (AF279254) were used to synthesize antisense RNA probes labeled with digoxigenin. In situ hybridization was performed as described previously [61]. Following in situ hybridization, Isl1/2 was detected by immunohistochemistry using mouse anti-Isl1/2 antibody (mixture of 39.4D5 and 40.2D6) and VECTASTAIN Kit (Vector Laboratories, Burlingame, USA).

\section{Retrograde-labeling of the neurite projection}

Retrograde-labeling was performed as described previously [61] with slight modifications as follows. E11.5 mouse embryos were dissected and cultured in mouse Ringer's solution oxygenated with carbogen $\left(95 \% \mathrm{O}_{2}\right.$ plus $\left.5 \% \mathrm{CO}_{2}\right)$ for 30 minutes to heal any cut edges that may incorporate the dye. Then a slit was made from the surface ectoderm overlying somites through DRG at the level of the thoracolumbar region and filled with lysine-fixable $3000 \mathrm{MW}$ tetramethylrhodamine dextran (D3308, Molecular Probes/ Invitrogen). The embryos were cultured for another 6 to 10 hours at room temperature to permit retrograde transport of the label and then fixed for immunofluorescence.

\section{GR-mediated activation of Six 1 in Xenopus embryo} GR cDNA was amplified from pSP64T-MyoDGR [53] by PCR and inserted into pCS2+ harboring an ORF of $X$. laevis six1 (AF279254) to generate a cDNA encoding Cterminal GR fusion $X$. laevis Six1 protein. The mRNA preparation, embryo manipulation and microinjection were performed as described in detail previously [94]. A total of 100 to $250 \mathrm{pg} /$ embryo of $\beta$-globin or 100 to $125 \mathrm{pg} /$ embryo of Six1-GR mRNA was co-injected with 400 pg/embryo of EGFP mRNA.

\section{siRNA-mediated knockdown of Six 1 in vivo using electroporation}

The Stealth RNAi siRNA Negative Control Med GC Duplex and Stealth siRNAs targeted to Xenopus six 1 were purchased from Invitrogen. A mixture of equimolar amounts of si1 through si3 (Figure 2M) was used for validation (Additional file $2 \mathrm{C}$ ) and in vivo electroporation. Xenopus embryos were anesthetized with $0.075 \%$ ethyl-3-aminobenzoate methanesulfonate (Tokyo Chemical Industry, Tokyo, Japan) dissolved in $0.1 \times$ Modified
Barth's Saline (MBS) and then transferred into an electrode chamber filled with $0.1 \times$ MBS. The anode and cathode platinum electrodes $(5 \mathrm{~mm}$ in height and $10 \mathrm{~mm}$ in width) were fixed on a glass dish with a $15 \mathrm{~mm}$ gap and integrated into a resin to establish a square chamber (CUY520P15, Nepa Gene, Ichikawa, Japan). siRNA negative control (200 to $400 \mu \mathrm{M})$ mixed with mRFP1 mRNA $(150 \mathrm{ng} / \mu \mathrm{l})$ as a control, or Six1 siRNAs $(200$ to $400 \mu \mathrm{M})$ mixed with mRFP1 mRNA or mutated Six 1 mRNA $(150 \mathrm{ng} / \mu \mathrm{l})$ were injected into the region between the spinal cord and dorsal ectoderm in the trunk using a glass micropipette. Just after injection, the dorsoventral axis of the embryos was aligned to the current direction and then electric pulses were applied at $105 \mathrm{~V}$, with $50 \mathrm{~ms}$ length, $950 \mathrm{~ms}$ interval, and 5 shocks by the electroporator, CUY-21 (Nepa Gene). Embryos were cultured in $0.1 \times \mathrm{MBS}$ at $19^{\circ} \mathrm{C}$.

\section{Generation of point mutations for Six 1}

To abolish the knockdown effect mediated by all Six1 siRNAs, three silent mutations in each siRNA-targeted regions were introduced (Figure $2 \mathrm{M}$ ). The PCR primers were designed to contain mutations and used to amplify DNA fragments. The DNA fragments were joined using In-Fusion HD Cloning Kit (Clontech/TaKaRa, Otsu, Japan), with the protocol supplied by the manufacturer, and verified by DNA sequencing.

\section{Time-lapse live imaging on trunk slice culture}

Live imaging analysis was performed as described previously [95] with slight modifications as follows. Transverse slices of E11 thoracolumbar region (approximately $300 \mu \mathrm{m}$ ) were prepared using Gastromaster microdissection device (GST-1, Nepa Gene). Scanning was performed with a 10x objective lens in the interval of 7.5 minutes using FV1000 (Olympus) laser confocal microscope.

\section{Construction of $x$ Six 1-8 and mSix 1-8 plasmids}

The enhancer sequences of Xenopus Six1-8 (JGI4.1:scaffold_68 3239865-3240552) and mouse Six1-8 (chromosome:NCBIM37: 12:74156389-74156926) were amplified from $X$. tropicalis and mouse genomes [74], respectively, by PCR and cloned into the ISpBSIISK + $\beta$ GFP vector [75]. The nomenclature of enhancer sequences was based on a previous report [74].

\section{Generation and analysis of transgenic Xenopus}

Transgenic Xenopus embryos were generated as described previously [75]. EGFP expression was detected using a rabbit anti-EGFP antibody (1:2,000 dilution, MBL, Nagoya, Japan). 


\section{Statistical analysis}

All values are expressed as mean \pm standard error of the mean of at least three independent assays or littermates. Differences from the control experiments were evaluated with Student's t-test. A probability of less than 5\% was considered statistically significant.

\section{Additional files}

\section{Additional file 1: Absence of six gene expression in the dorsal} neural tube of Xenopus embryo during early development. (A,B) six1, (C,D) six4 (AF276994) and (E,F) six4 (AF276995) mRNAs are not detected by whole-mount in situ hybridization (purple staining) in the dorsal neural tube of Xenopus embryos at St. 16/17 (A,C,E) and 25/26 (B,D,F). Left: rostral side. Scale bars: $0.5 \mathrm{~mm}$.

Additional file 2: Gain- and loss-of-function of Six1 affects primary sensory development. (A) Schematic representation of GR-mediated activation of Six1. (B) Immunofluorescence of Tlx3 and Kcna1 in Xenopus primary sensory neurons. The nuclei and cytoplasm of Xenopus RB cells (arrowheads) are labeled with anti-Is|1/2 (green) and HNK-1 (magenta), respectively. Tlx3 (green) and Kcna1 (green) are also detected in the nuclei and the cell membrane/cytoplasm of these cells, respectively. DRG neurons are positive for both IsI1/2 (green) and TIx3 (magenta). Scale bars: $25 \mu \mathrm{m}$. (C) Verification of the knockdown efficacy of a mixture of Six 1 siRNAs and the resistance of mutated Six 1 to Six 1 siRNAs. Plasmids containing the FLAG-tagged Six1 (pCS2-FLAG-Six1) or the mutated Six1 (pCS2-FLAG-Six1-silent, Figure 2M) are transfected into HEK293 cell line with negative control siRNA (nega.ctrl.si) or a mixture of Six1 siRNAs (Six1 siRNAs). The expression plasmid for EGFP ( $p E G F P$ ) is co-transfected to monitor the efficiency of transfection. Protein levels are determined by western blotting using anti-FLAG and anti-EGFP antibodies. The signal intensity is analyzed densitometrically and displayed in bar graph, normalized to EGFP level and expressed relative to that of negative control siRNA. Note that Six 1 siRNAs show efficient protein knockdown, which is abolished by mutations in the siRNA target sequences. (D) Reduction of RB cell number in the trunk region. Xenopus development is associated with a fall in the total number of RB cells located in the entire spinal cord, starting at St. 46 [9]. To analyze the phenotypes in electropolated area, the number of RB cells in the spinal cord at the level of somites 1 through 9 (between two red lines) is re-evaluated and displayed in bar graph ( $n=5$ for each stage, data are mean \pm standard error of the mean). Cell numbers started to decrease earlier than that of whole spinal cord. Scale bar: $1 \mathrm{~mm}$.

\section{Additional file 3: Both SIX1 and SIX4 are expressed in DRG. (A)}

Specificities of anti-SIX1 and anti-SIX4 antibodies are validated by using Six 1 or Six4 single homozygous knockout mice, Six $1^{-/-}$or Six $4^{-1-}$. To evaluate the specificities of the antibodies, the trigeminal ganglia $(\mathrm{Vg})$ are subjected to immunofluorescence staining, in which both SIX 1 and SIX4 are expressed during the development [48]. The rat polyclonal antibody against mouse SIX1 [48] detects SIX1 protein in Six4 ${ }^{-/-}$embryo (denoted as Six4 $4^{\text {LaCZ/LacZ) }}$ [50], but not in Six $1^{-/-}$embryo (denoted as Six $1^{\text {EGFP/EGFP) }}$ [41]. The guinea pig polyclonal antibody against mouse SIX4 [39] recognizes SIX4 in SIX $1^{\text {EGFP/EGFP }}$ embryo, but none in Six $4^{\text {LacZ/LacZ }}$. These results show lack of cross-reactivity of anti-SIX 1 and anti-SIX 4 antibodies with SIX4 and SIX1, respectively. Bottom line shows merged images; SIX1 and SIX4 in wild type, EGFP expressed from Six 1 knockout alleles and SIX4 in SiX ${ }^{\text {EGFP/EGFP }}$, SIX1 and $\beta$-galactosidase expressed from Six4 knockout alleles in Six4 ${ }^{\text {LacZ/LacZ }}$. Scale bars: $50 \mu \mathrm{m}$. (B) Similar distribution of SIX1 and SIX4 in developing mouse DRG. In E11.5 mouse embryo, the majority of SIX1-positive-cells in DRG (green) are labeled with SIX4 immunofluorescence (magenta), as shown in the merged panel. The relative intensities of immunofluorescent signals for SIX1 and SIX4 vary among DRG neurons. Dashed lines demarcate the position of the ectoderm and spinal cord (sc). Scale bar: $50 \mu \mathrm{m}$.

Additional file 4: Intramedullary EGFP-positive cells in Six 1/4 EGFP/EGFP mice are positive for RUNX1, RUNX3 cleaved CASP3 and NRP1. (A) The majority of intramedullary EGFP-positive cells in Six $1 / 4^{\text {EGFP/EGFP }}$ embryos (green in spinal cord (sc)) are positive for RUNX1 (magenta) and RUNX3 (magenta), as pointed out with arrowheads. Top line shows embryonic days of embryos. RUNX3 is detected at E11, one day earlier than that of RUNX1. (B) A substantial number of cleaved CASP3 (cCasp3)-positive cells (magenta) are observed in the spinal cords of Six 1/ $4^{\text {EGFPIEGFP }}$ at E12 and these cells are also positive for EGFP (green, arrowheads), whereas no such cells are observed in the Six $1 / 4^{+/ E G F P}$ spinal cord. (C) The majority of intramedullary EGFP-positive cells in Six1/ $4^{E G F P / E G F P}$ embryos (green in Sc) are positive for NRP1 (magenta), but not for NRP2 (magenta), as indicated by arrowheads. Dashed lines demarcate the position of the ectoderm and Sc. Scale bars: $50 \mu \mathrm{m}$.

Additional file 5: Medial migration of EGFP-positive cells of Six1/ $4^{\text {EGFP/EGFP }}$. Time-lapse confocal microscopy images of EGFP-positive cells on slice culture of E11 Six $1 / 4^{\text {EGFP/EGFP }}$ lumbar region were acquired every 7.5 minutes for 8 hours and animated in $60 \mathrm{~ms} /$ frame. Snapshots at the indicated time points are shown in Figure 61 . The animated sequence that harbors the dotted line demarcating the edge of the spinal cord and magenta-filled square and triangle pointing to EGFP-positive cells follows the one without any labels.

Additional file 6: Number but not length of individual laminin gaps

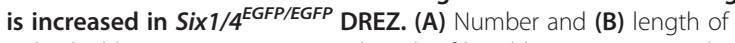
individual laminin gaps in $50 \mu \mathrm{m}$ length of basal lamina covering the primordium of the dorsal funiculus. For all measurements, at least five sections from three embryos were used per genotype. Data are mean \pm standard error of the mean. ${ }^{*} p<0.005$.

\section{Abbreviations}

BC: boundary cap; CNS: central nervous system; Dex: dexamethasone; DREZ: dorsal root entry zone; DRG: dorsal root ganglia; E: embryonic day; EGFP: enhanced green fluorescent protein; GR: glucocorticoid receptor ligand-binding domain; MEP: motor exit point; mRFP: monomeric red fluorescent protein; MBS: Modified Barth's saline; NCC: neural crest cell; ORF: open reading frame; PCR: polymerase chain reaction; PNS: peripheral nervous system; RB: Rohon-Beard; siRNA: small interfering RNA; St: Stage.

\section{Competing interests}

The authors declare that they have no competing interests.

\section{Authors' contributions}

HY was involved in the conception and design, data collection, analysis and interpretation, and manuscript writing; MS, HOc, $\mathrm{HOg}$ and $\mathrm{NU}$ in data collection and data analysis; $\mathrm{KI}$ and $\mathrm{KY}$ in provision of study material; SS in data interpretation and provision of study material; KK in conception and design, data analysis and interpretation, and manuscript writing. All authors read and approved the final manuscript.

\section{Acknowledgments}

The authors thank M Akima, H Ikeda, Y Suto and K Mogi for the technical assistance; C Birchmeier for TLX3 antibody; HL Sive for pSP64T-MyoDGR plasmid; H Yokoyama and K Tamura for Xenopus embryos; K Sharma and M Yamakado for helpful advice; M Takahashi and K Tamura for comments on the manuscript; and S Yonei-Tamura for the schematic diagrams. This work was supported by grants from MEXT (\#18390061 to KK, \#19790156, \#21790189, \#23790234 and \#25460251 to HY), the NIBB Cooperative Research Program (8-134), Jichi Medical University Young Investigator Award, MEXT-Supported Program for the Strategic Research Foundation at Platform in Private Universities (2008-2012) and JST-CREST (to HOg).

\section{Author details}

'Division of Biology, Center for Molecular Medicine, Jichi Medical University, 3311-1 Yakushiji, Shimotsuke, Tochigi 329-0498, Japan. ²Division of Morphogenesis, Department of Developmental Biology, National Institute for Basic Biology, 38 Nishigonaka, Myodaiji, Okazaki, Aichi 444-8585, Japan. ${ }^{3}$ Faculty of Medicine, Yamagata University, 2-2-2 lida-Nishi, Yamagata 990-9585, Japan. ${ }^{4}$ Division of Developmental Genetics, Center for Animal Resources and Development, Institute of Resource Development and Analysis, Kumamoto University, 2-2-1 Honjo, Kumamoto 860-0811, Japan. ${ }^{5}$ Department of Animal Bioscience, Nagahama Institute of Bio-Science and Technology, 1266 Tamura, Nagahama, Shiga 526-0829, Japan. 
Received: 7 May 2014 Accepted: 22 May 2014

Published: 29 May 2014

\section{References}

1. Beard J: On the early development of Lepidosteus osseus - preliminary notice. Proc $R$ Soc Lond 1889, 46:108-118.

2. Bernhardt RR, Chitnis $A B$, Lindamer L, Kuwada JY: Identification of spinal neurons in the embryonic and larval zebrafish. J Comp Neurol 1990, 302:603-616.

3. Coghill GE: Correlated anatomical and physiological studies on the growth of the nervous system of Amphibia. 1. The afferent system of the trunk of Amblystoma. J Comp Neurol 1914, 24:161-233.

4. Hughes A: The development of the primary sensory system in Xenopus laevis (Daudin). J Anat 1957, 91:323-338.

5. Eccles JC, Schadé JP: Organization of the Spinal Cord. Amsterdam: Elsevier; 1964.

6. Ariëns Kappers CU, Huber GC, Crosby EC: The Comparative Anatomy of the Nervous System of Vertebrates, Including Man. New York: Hafner; 1967 (Originally published in 1936).

7. Fritzsch B, Northcutt RG: Cranial and spinal nerve organization in amphioxus and lampreys: evidence for an ancestral craniate pattern. Acta Anat (Basel) 1993, 148:96-109.

8. Hartenstein V: Early pattern of neuronal differentiation in the Xenopus embryonic brainstem and spinal cord. J Comp Neurol 1993, 328:213-231.

9. Lamborghini JE: Disappearance of Rohon-Beard neurons from the spinal cord of larval Xenopus laevis. J Comp Neurol 1987, 264:47-55.

10. Bone Q: The central nervous system in larval acraniates. Q J Microsc Sci 1959, 100:509-527.

11. Lacalli TC, Kelly SJ: Sensory pathways in amphioxus larvae II. Dorsal tracts and translumenal cells. Acta Zool-Stockholm 2003, 84:1-13.

12. Bone Q: The central nervous system in amphioxus. J Comp Neurol 1960, 115:27-64.

13. Johnston JB: The cranial and spinal ganglia and the viscero-motor roots in amphioxus. Biol Bull 1905, 9:112-127.

14. Whiting HP: Nervous structure of the spinal cord of the young larval brook-lamprey. Q J Microsc Sci 1948, 89:359-383.

15. Nakao T, Ishizawa A: Development of the spinal nerves in the lamprey: I. Rohon-Beard cells and interneurons. J Comp Neurol 1987, 256:342-355.

16. Beard J: The transient ganglion cells and their nerves in Raja batis. Anat Anzeiger 1892, 7:191-206.

17. Kuratani S, Horigome N: Developmental morphology of branchiomeric nerves in a cat shark, Scyliorhinus torazame, with special reference to rhombomeres, cephalic mesoderm, and distribution patterns of cephalic crest cells. Zoo/ Sci 2000, 17:893-909.

18. Kuwada JY, Bernhardt RR, Nguyen N: Development of spinal neurons and tracts in the zebrafish embryo. J Comp Neurol 1990, 302:617-628.

19. Eichler VB, Porter RA: Rohon-Beard cells in frog development: a study of temporal and spatial changes in a transient cell population. J Comp Neurol 1981, 203:121-130.

20. Forehand CJ, Farel PB: Spinal cord development in anuran larvae: I. Primary and secondary neurons. J Comp Neurol 1982, 209:386-394.

21. Kollros JJ, Bovbjerg AM: Growth and death of Rohon-Beard cells in Rana pipiens and Ceratophrys ornata. J Morphol 1997, 232:67-78.

22. Schlosser G, Roth G: Evolution of nerve development in frogs. II. Modified development of the peripheral nervous system in the direct-developing frog Eleutherodactylus coqui (Leptodactylidae). Brain Behav Evol 1997, 50:94-128.

23. Rossi CC, Hernandez-Lagunas L, Zhang C, Choi IF, Kwok L, Klymkowsky M, Artinger KB: Rohon-Beard sensory neurons are induced by BMP4 expressing non-neural ectoderm in Xenopus laevis. Dev Bio/ 2008, 314:351-361.

24. Cornell RA, Eisen JS: Delta signaling mediates segregation of neural crest and spinal sensory neurons from zebrafish lateral neural plate. Development 2000, 127:2873-2882.

25. Cornell RA, Eisen JS: Delta/Notch signaling promotes formation of zebrafish neural crest by repressing Neurogenin 1 function. Development 2002, 129:2639-2648.

26. Theveneau $E$, Mayor R: Neural crest delamination and migration: from epithelium-to-mesenchyme transition to collective cell migration. Dev Biol 2012, 366:34-54.
27. Davidson LA, Keller RE: Neural tube closure in Xenopus laevis involves medial migration, directed protrusive activity, cell intercalation and convergent extension. Development 1999, 126:4547-4556.

28. Rossi CC, Kaji T, Artinger KB: Transcriptional control of Rohon-Beard sensory neuron development at the neural plate border. Dev Dyn 2009, 238:931-943.

29. Tanaka H, Morimura R, Ohshima T: DpysI2 (CRMP2) and Dpysl3 (CRMP4) phosphorylation by Cdk5 and DYRK2 is required for proper positioning of Rohon-Beard neurons and neural crest cells during neurulation in zebrafish. Dev Biol 2012, 370:223-236.

30. Metcalfe WK, Myers PZ, Trevarrow B, Bass MB, Kimmel CB: Primary neurons that express the L2/HNK-1 carbohydrate during early development in the zebrafish. Development 1990, 110:491-504.

31. Ribera AB, Nusslein-Volhard C: Zebrafish touch-insensitive mutants reveal an essential role for the developmental regulation of sodium current. J Neurosci 1998, 18:9181-9191.

32. Williams JA, Barrios A, Gatchalian C, Rubin L, Wilson SW, Holder N: Programmed cell death in zebrafish rohon beard neurons is influenced by TrkC1/NT-3 signaling. Dev Biol 2000, 226:220-230.

33. Klymkowsky MW, Rossi CC, Artinger KB: Mechanisms driving neural crest induction and migration in the zebrafish and Xenopus laevis. Cell Adh Migr 2010, 4:595-608.

34. Bricaud $O$, Collazo $A$ : The transcription factor six 1 inhibits neuronal and promotes hair cell fate in the developing zebrafish (Danio rerio) inner ear. J Neurosci 2006, 26:10438-10451.

35. Bricaud $\mathrm{O}$, Collazo A: Balancing cell numbers during organogenesis: Six1a differentially affects neurons and sensory hair cells in the inner ear. Dev Biol 2011, 357:191-201.

36. Schlosser G, Awtry T, Brugmann SA, Jensen ED, Neilson K, Ruan G, Stammler A, Voelker D, Yan B, Zhang C, Klymkowsky MW, Moody SA: Eya1 and Six1 promote neurogenesis in the cranial placodes in a SoxB1-dependent fashion. Dev Biol 2008, 320:199-214.

37. Brugmann SA, Pandur PD, Kenyon KL, Pignoni F, Moody SA: Six 1 promotes a placodal fate within the lateral neurogenic ectoderm by functioning as both a transcriptional activator and repressor. Development 2004, 131:5871-5881.

38. Ikeda K, Kageyama R, Suzuki Y, Kawakami K: Six1 is indispensable for production of functional progenitor cells during olfactory epithelial development. Int J Dev Biol 2010, 54:1453-1464.

39. Ikeda K, Ookawara S, Sato S, Ando Z, Kageyama R, Kawakami K: Six1 is essential for early neurogenesis in the development of olfactory epithelium. Dev Biol 2007, 311:53-68.

40. Laclef C, Souil E, Demignon J, Maire P: Thymus, kidney and craniofacial abnormalities in Six 1 deficient mice. Mech Dev 2003, 120:669-679.

41. Ozaki H, Nakamura K, Funahashi J, Ikeda K, Yamada G, Tokano H, Okamura HO, Kitamura K, Muto S, Kotaki H, Sudo K, Horai R, Iwakura Y, Kawakami K: Six1 controls patterning of the mouse otic vesicle. Development 2004, 131:551-562

42. Zheng $W$, Huang L, Wei ZB, Silvius D, Tang B, Xu PX: The role of Six 1 in mammalian auditory system development. Development 2003 130:3989-4000.

43. Zou D, Silvius D, Fritzsch B, Xu PX: Eya1 and Six 1 are essential for early steps of sensory neurogenesis in mammalian cranial placodes. Development 2004, 131:5561-5572.

44. Ito T, Noguchi Y, Yashima T, Kitamura K: SIX1 mutation associated with enlargement of the vestibular aqueduct in a patient with branchio-oto syndrome. Laryngoscope 2006, 116:796-799.

45. Ruf RG, Xu PX, Silvius D, Otto EA, Beekmann F, Muerb UT, Kumar S, Neuhaus TJ, Kemper MJ, Raymond RM Jr, Brophy PD, Berkman J, Gattas M, Hyland V, Ruf EM, Schwartz C, Chang EH, Smith RJ, Stratakis CA, Weil D, Petit C, Hildebrandt F: SIX1 mutations cause branchio-oto-renal syndrome by disruption of EYA1-SIX1-DNA complexes. Proc Natl Acad Sci U S A 2004, 101:8090-8095.

46. Kochhar A, Orten DJ, Sorensen JL, Fischer SM, Cremers CW, Kimberling WJ, Smith RJ: SIX1 mutation screening in 247 branchio-oto-renal syndrome families: a recurrent missense mutation associated with BOR. Hum Mutat 2008, 29:565.

47. Kobayashi H, Kawakami K, Asashima M, Nishinakamura R: Six1 and Six4 are essential for Gdnf expression in the metanephric mesenchyme and ureteric bud formation, while Six 1 deficiency alone causes mesonephric-tubule defects. Mech Dev 2007, 124:290-303.

48. Konishi Y, Ikeda K, Iwakura Y, Kawakami K: Six1 and Six4 promote survival of sensory neurons during early trigeminal gangliogenesis. Brain Res 2006, 1116:93-102. 
49. Zou D, Silvius D, Davenport J, Grifone R, Maire P, Xu PX: Patterning of the third pharyngeal pouch into thymus/parathyroid by Six and Eya1. Dev Biol 2006, 293:499-512

50. Ozaki H, Watanabe Y, Takahashi K, Kitamura K, Tanaka A, Urase K, Momoi T, Sudo K, Sakagami J, Asano M, Iwakura Y, Kawakami K: Six4, a putative myogenin gene regulator, is not essential for mouse embryonal development. Mol Cell Biol 2001, 21:3343-3350.

51. Korzh $V$, Edlund $T$, Thor S: Zebrafish primary neurons initiate expression of the LIM homeodomain protein Is|-1 at the end of gastrulation. Development 1993, 118:417-425.

52. Inoue A, Takahashi M, Hatta K, Hotta Y, Okamoto H: Developmental regulation of islet-1 mRNA expression during neuronal differentiation in embryonic zebrafish. Dev Dyn 1994, 199:1-11.

53. Kolm PJ, Sive HL: Efficient hormone-inducible protein function in Xenopus laevis. Dev Biol 1995, 171:267-272.

54. Jacobson M: Rohon-Beard neuron origin from blastomeres of the 16-cell frog embryo. J Neurosci 1981, 1:918-922.

55. Lamborghini JE: Rohon-beard cells and other large neurons in Xenopus embryos originate during gastrulation. J Comp Neurol 1980, 189:323-333.

56. Patterson KD, Krieg PA: Hox11-family genes XHox11 and XHox11L2 in Xenopus: XHox11L2 expression is restricted to a subset of the primary sensory neurons. Dev Dyn 1999, 214:34-43.

57. Suzuki Y, Ikeda K, Kawakami K: Expression of Six1 and Six4 in mouse taste buds. J Mol Histol 2010, 41:205-214.

58. Ando Z, Sato S, Ikeda K, Kawakami K: SIc12a2 is a direct target of two closely related homeobox proteins, Six1 and Six4. FEBS J 2005, 272:3026-3041.

59. Ozaki S, Snider WD: Initial trajectories of sensory axons toward laminar targets in the developing mouse spinal cord. J Comp Neurol 1997, 380:215-229.

60. Mu X, Silos-Santiago I, Carroll SL, Snider WD: Neurotrophin receptor genes are expressed in distinct patterns in developing dorsal root ganglia. J Neurosci 1993, 13:4029-4041.

61. Sharma K, Sheng HZ, Lettieri K, Li H, Karavanov A, Potter S, Westphal H, Pfaff SL: LIM homeodomain factors Lhx3 and Lhx4 assign subtype identities for motor neurons. Cell 1998, 95:817-828.

62. Muller T, Anlag K, Wildner H, Britsch S, Treier M, Birchmeier C: The bHLH factor Olig3 coordinates the specification of dorsal neurons in the spinal cord. Genes Dev 2005, 19:733-743.

63. Ribera $A B$, Nguyen DA: Primary sensory neurons express a Shaker-like potassium channel gene. J Neurosci 1993, 13:4988-4996.

64. Park BY, Hong CS, Weaver JR, Rosocha EM, Saint-Jeannet JP: Xaml1/Runx1 is required for the specification of Rohon-Beard sensory neurons in Xenopus. Dev Biol 2012, 362:65-75.

65. Park BY, Saint-Jeannet JP: Expression analysis of Runx3 and other Runx family members during Xenopus development. Gene Expr Patterns 2010, 10:159-166.

66. Heathcote $\mathrm{RD}$, Chen $\mathrm{A}$ : A nonrandom interneuronal pattern in the developing frog spinal cord. J Comp Neurol 1993, 328:437-448.

67. Yamauchi Y, Abe K, Mantani A, Hitoshi Y, Suzuki M, Osuzu F, Kuratani S, Yamamura K: A novel transgenic technique that allows specific marking of the neural crest cell lineage in mice. Dev Biol 1999, 212:191-203.

68. Niederlander C, Lumsden A: Late emigrating neural crest cells migrate specifically to the exit points of cranial branchiomotor nerves. Development 1996, 122:2367-2374.

69. Vermeren M, Maro GS, Bron R, McGonnell IM, Charnay P, Topilko P, Cohen J: Integrity of developing spinal motor columns is regulated by neural crest derivatives at motor exit points. Neuron 2003, 37:403-415.

70. Maro GS, Vermeren M, Voiculescu O, Melton L, Cohen J, Charnay P, Topilko P. Neural crest boundary cap cells constitute a source of neuronal and glial cells of the PNS. Nat Neurosci 2004, 7:930-938.

71. Coulpier F, Decker L, Funalot B, Vallat JM, Garcia-Bragado F, Charnay P, Topilko P: CNS/PNS boundary transgression by central glia in the absence of Schwann cells or Krox20/Egr2 function. J Neurosci 2010, 30:5958-5967.

72. Schneider-Maunoury S, Topilko P, Seitandou T, Levi G, Cohen-Tannoudji M, Pournin S, Babinet C, Charnay P: Disruption of Krox-20 results in alteration of rhombomeres 3 and 5 in the developing hindbrain. Cell 1993, 75:1199-1214.

73. Golding JP, Cohen J: Border controls at the mammalian spinal cord: late-surviving neural crest boundary cap cells at dorsal root entry sites may regulate sensory afferent ingrowth and entry zone morphogenesis. Mol Cell Neurosci 1997, 9:381-396.
74. Sato S, Ikeda K, Shioi G, Nakao K, Yajima H, Kawakami K: Regulation of Six1 expression by evolutionarily conserved enhancers in tetrapods. Dev Biol 2012, 368:95-108.

75. Ogino H, Fisher M, Grainger RM: Convergence of a head-field selector Otx2 and Notch signaling: a mechanism for lens specification. Development 2008, 135:249-258.

76. Kanungo J, Li BS, Zheng Y, Pant HC: Cyclin-dependent kinase 5 influences Rohon-Beard neuron survival in zebrafish. J Neurochem 2006, 99:251-259.

77. Humphrey T: Primitive neurons in the embryonic human central nervous system. J Comp Neurol 1944, 81:1-45.

78. Youngstrom KA: Intramedullary sensory type ganglion cells in the spinal cord of human embryos. J Comp Neurol 1944, 81:47-53.

79. Donoghue PC, Graham A, Kelsh RN: The origin and evolution of the neural crest. Bioessays 2008, 30:530-541.

80. Chen CL, Broom DC, Liu Y, de Nooij JC, Li Z, Cen C, Samad OA, Jessell TM, Woolf $\mathrm{CJ}, \mathrm{Ma} \mathrm{Q}$ : Runx1 determines nociceptive sensory neuron phenotype and is required for thermal and neuropathic pain. Neuron 2006, 49:365-377.

81. Gammill LS, Roffers-Agarwal J: Division of labor during trunk neural crest development. Dev Biol 2010, 344:555-565.

82. Kuriyama S, Mayor R: Molecular analysis of neural crest migration. Philos Trans R Soc Lond B Biol Sci 2008, 363:1349-1362.

83. Kawasaki T, Bekku Y, Suto F, Kitsukawa T, Taniguchi M, Nagatsu I, Nagatsu T, Itoh K, Yagi T, Fujisawa H: Requirement of neuropilin 1-mediated Sema3A signals in patterning of the sympathetic nervous system. Development 2002, 129:671-680

84. Gammill LS, Gonzalez C, Gu C, Bronner-Fraser M: Guidance of trunk neural crest migration requires neuropilin 2 /semaphorin $3 \mathrm{~F}$ signaling. Development 2006, 133:99-106.

85. Roffers-Agarwal J, Gammill LS: Neuropilin receptors guide distinct phases of sensory and motor neuronal segmentation. Development 2009, 136:1879-1888.

86. Koestner U, Shnitsar I, Linnemannstons K, Hufton AL, Borchers A: Semaphorin and neuropilin expression during early morphogenesis of Xenopus laevis. Dev Dyn 2008, 237:3853-3863.

87. Kozmik Z, Holland ND, Kreslova J, Oliveri D, Schubert M, Jonasova K, Holland LZ, Pestarino M, Benes V, Candiani S: Pax-Six-Eya-Dach network during amphioxus development: conservation in vitro but context specificity in vivo. Dev Biol 2007, 306:143-159.

88. Carroll SB: Evo-devo and an expanding evolutionary synthesis: a genetic theory of morphological evolution. Cell 2008, 134:25-36

89. Koshiba-Takeuchi K, Mori AD, Kaynak BL, Cebra-Thomas J, Sukonnik T, Georges RO, Latham S, Beck L, Henkelman RM, Black BL, Olson EN, Wade J, Takeuchi JK, Nemer M, Gilbert SF, Bruneau BG: Reptilian heart development and the molecular basis of cardiac chamber evolution. Nature 2009, 461:95-98.

90. Shim S, Kwan KY, Li M, Lefebvre V, Sestan N: Cis-regulatory control of corticospinal system development and evolution. Nature 2012, 486:74-79.

91. Freitas R, Gomez-Marin C, Wilson JM, Casares F, Gomez-Skarmeta JL: Hoxd13 contribution to the evolution of vertebrate appendages. Dev Cell 2012, 23:1219-1229.

92. Sive HL, Grainger RM, Harland RM: Early Development of Xenopus laevis. New York: Cold Spring Harbor Laboratory Press; 2000.

93. Nieuwkoop PD, Faber J: Normal Table of Xenopus laevis (Daudin). Amsterdam: North-Holland Publishing Company; 1967.

94. Suzuki M, Hara Y, Takagi C, Yamamoto TS, Ueno N: MID1 and MID2 are required for Xenopus neural tube closure through the regulation of microtubule organization. Development 2010, 137:2329-2339.

95. Takahashi M, Osumi N: Live Imaging of neuroepithelial cells in the rat spinal cord by confocal laser-scanning microscopy. In Bionanotechnology Based Future Medical Engineering Proceedings of the Final Symposium of the Tohoku University 21st Century Center of Excellence Program. London: Imperial College Press; 2006:211-220.

doi:10.1186/1741-7007-12-40

Cite this article as: Yajima et al: Six1 is a key regulator of the developmental and evolutionary architecture of sensory neurons in craniates. BMC Biology 2014 12:40 